\title{
The crystal structure of the varicella zoster Orf24-Orf27 nuclear egress complex spotlights multiple determinants of herpesvirus subfamily specificity
}

Johannes Schweininger1, \#, Mark Kriegel ${ }^{1,}$ \#, Sigrun Häge², Marcus Conrad ${ }^{3}$, Sewar Alkhashrom $^{4}$, Josephine Lösing ${ }^{2}$, Sigrid Weiler1, Julia Tillmanns², Claudia Egerer-Sieber ${ }^{1}$, Andrea Decker ${ }^{1}$, Tihana Lenac Roviš ${ }^{5}$, Jutta Eichler ${ }^{4}$, Heinrich Sticht ${ }^{3}$, Manfred Marschall, $^{2,}$, Yves A. Muller ${ }^{1, *}$

${ }^{1}$ Division of Biotechnology, Department of Biology, Friedrich-Alexander-Universität ErlangenNürnberg (FAU), Erlangen, Germany.

2 Institute for Clinical and Molecular Virology, Friedrich-Alexander-Universität ErlangenNürnberg (FAU), Medical Center Erlangen, Germany.

${ }^{3}$ Division of Bioinformatics, Institute of Biochemistry, Friedrich-Alexander-Universität ErlangenNürnberg (FAU), Erlangen, Germany.

${ }^{4}$ Department of Chemistry and Pharmacy, Friedrich-Alexander-Universität Erlangen-Nürnberg (FAU), Erlangen, Germany.

${ }^{5}$ Center for Proteomics, Faculty of Medicine, University of Rijeka, Rijeka, Croatia.

\# These authors contributed equally to this work

* To whom correspondence should be addressed: M. Marschall, Y.A. Muller Email: manfred.marschall@fau.de,yves.muller@fau.de

RUNNING TITLE: The structure of the varicella zoster Orf24-Orf27 core NEC 


\section{ABSTRACT}

Varicella zoster virus (VZV) is a human pathogen from the $\alpha$-subfamily of herpesviruses. Here, the crystal structure of the VZV Orf24-Orf27 complex is described, representing the essential viral core nuclear egress complex (NEC) that orchestrates the egress of the preassembled capsids from the nucleus. While previous studies have primarily emphasized the finding that the architecture of core NEC complexes is highly conserved among herpesviruses, the present report focusses on subfamily-specific structural and functional features that help explain the differences in the autologous versus nonautologous interaction patterns observed for NEC formation across herpesviruses. CoIP and confocal imaging data show that Orf24-Orf27 complex formation displays some promiscuity in a herpesvirus subfamily-restricted manner. At the same time, analysis of the NEC formation thermodynamic parameters of three prototypical $\alpha$-, $\beta$ - and $\gamma$ herpesviruses, i.e. VZV, human cytomegalovirus (HCMV) and Epstein-Barr virus (EBV) reveals highly similar binding affinities for the autologous interaction with some specific differences in the enthalpy and entropy terms. Computational alanine scanning and structural comparisons highlight intermolecular interactions shared among $\alpha$-herpesviruses that are clearly distinct from those seen in $\beta$ - and $\gamma$-herpesviruses. Combined, these data allow to explain the distinct properties of specificity and permissivity so far observed in herpesviral NEC interactions. These findings might prove highly valuable when attempting to target multiple herpesvirus core NECs with selective or broad-acting drug candidates. 


\section{INTRODUCTION}

Members of the family Herpesviridae are membrane-enveloped viruses, characterized by a comparably large particle size (100-300 nm) and a linear double-stranded DNA genome. The nine presently known human herpesviruses can be assigned to three subfamilies, i.e. the $\alpha$-, $\beta$ - and $\gamma$ Herpesvirinae, based on their morphology, genetics and biological properties (1). A typical feature of all herpesvirus infections is their lifelong persistence in the host with extended periods of latency followed by intermittent periods of reactivation. While most herpesviral infections may remain on subclinical or asymptomatic stages in immunocompetent persons, severe impairments of health can occur in older persons and/or those with a compromised immune system, such as patients suffering from AIDS/immunodeficiency virus type 1 infection (HIV-1), immunosuppressive treatment or cancer therapy. The present study focusses on the $\alpha$-herpesvirus varicella zoster virus (VZV, HHV3), which shows a seroprevalence of $>90 \%$ in the human population worldwide (2). VZV causes chickenpox (varicella) in children and persists in the nervous system of the immunocompetent host during latency. Upon reactivation, VZV leads to lesions known as shingles (zoster) and can cause severe neurological conditions such as acute sequelae or continuing burning pain. The prototype viruses of the $\beta$ - and $\gamma$-subfamilies are human cytomegalovirus (HCMV) and Epstein-Barr virus (EBV), respectively. HCMV has a seroprevalence of $40 \%$ to $95 \%$ in various parts of the world and congenital HCMV infections (cCMV) acquired during pregnancy can lead to stillbirth, severe birth defects in newborns as well as late-onset developmental retardation (3-5). EBV is the causative agent of infectious mononucleosis, and in addition EBV infections are associated with various, typically malignant tumors, such as Burkitt lymphoma, Hodgkin’s lymphoma, posttransplant B and $\mathrm{T}$ cell lymphoma, nasopharyngeal and gastric carcinoma (6). Animal herpesviruses such as bovine $\alpha$-herpesvirus 1 , equine herpesviruses or pseudorabies virus (PRV) can cause pathogenic infections in domesticated animals. These are often met by a strict culling policy causing severe economic repercussions (7-9). Although antiviral drugs and vaccines exist for combatting some herpesvirus infections, approved vaccines against HCMV and EBV are still missing, and in cases of clinically problematic VZV infections, antiviral therapy has not yet achieved the desired efficacy. Treatments are also under the continuous threat of the emergence of viral drug resistance or vaccine escape mutations. Hence, the identification of novel antiherpesviral drugs and targeting strategies remains a global research focus $(10,11)$. 
Common to all herpesviruses is the preassembly of capsids in the nucleus, whereas the final maturation of virions occurs in the cytosol and trans-Golgi membrane vesicles. Due to size constraints, intranuclear capsids cannot migrate from the nucleoplasm to the cytosol via the nuclear pore complex (NPC) but rely on the mechanism of nuclear egress that is regulated in a herpesvirusspecific manner $(12,13)$. This process starts with the formation of the core nuclear egress complex (core NEC) formed between two viral proteins, namely between a membrane-associated and a nucleoplasmic-soluble protein. The core NEC combines multiple regulatory aspects. For once, it functions as a scaffold platform for the recruitment of virus- and host cell-derived NEC-associated effector proteins that destabilize the lamina at the inner layer of the nuclear envelope and induce membrane fission $(13,14)$. Secondly, the complex associates to higher oligomers, specifically to hexameric and possibly pentameric arrangements, that induce capsid docking followed by budding through the inner nuclear membrane (15). Experimental structural data on the core NECs are so far available from the $\alpha$-herpesviruses herpes simplex virus type $1(\mathrm{HSV}-1)$ and PRV, the $\beta$ herpesvirus HCMV and the $\gamma$-herpesvirus EBV (Table S1) (16-20). A hallmark of all complexes is the so-called hook-into-groove interaction with the membrane-associated NEC protein (e.g. VZV Orf24) forming a groove-like interaction surface, onto which a contiguous segment from the nucleoplasmic-soluble NEC protein (e.g. VZV Orf27) binds in a hook-like manner $(3,13,21)$. The hook-like segment is approximately thirty residues long, is formed by two $\alpha$-helices and interacts with high affinity with the groove protein thus resulting in core NEC assembly (19). In all known characterized complexes, this interaction motif accounts for about $80 \%$ of the total number of interactions formed between the hook and the groove protein. The hook-into-groove interaction principle of NEC formation appears highly specific for individual herpesviruses. Interestingly, however, an experimental testing of selected examples of NEC protein interactions between herpesviruses in a nonautologous, cross-viral manner, revealed some promiscuity of interaction as observed for NEC protein pairs derived from members of the same subfamily (22). Because of the scarcity of currently available structural information, the structural determinants for the subfamilyspecific interaction pattern remains currently purely understood.

Here, we report the $2.1 \AA$ resolution crystal structure of the core NEC complex from $\alpha$ herpesvirus VZV, namely the complex formed between the grove protein Orf24 and the hook protein Orf27. Computational alanine scanning and structural comparisons between VZV and the previously reported $\alpha$-herpesviral NECs of HSV-1 and PRV revealed a number of shared 
intermolecular interaction features that clearly differed from those in the $\beta$-/ $\gamma$-herpesviral NECs of HCMV and EBV, respectively. Referring to functional aspects, an analysis by coimmunoprecipitation (CoIP) and confocal imaging (CLSM) colocalization showed that VZV Orf24-Orf27 complex formation displays some promiscuity regarding binding to other $\alpha$ herpesviral NEC protein binding partners, while this is not the case with regard to nonautologous interactions between core NEC proteins belonging to different herpesviral subfamilies. These findings thus confirm initial data reported earlier and explain both, the distinct properties and specificity restrictions so far observed by various studies on herpesviral NEC interactions.

\section{RESULTS}

\section{Molecular characteristics of the $\alpha$-, $\beta$ - and $\gamma$-herpesviral core NEC proteins as expressed in cell culture-based viral infection models}

We used $\alpha$ - (VZV), $\beta$ - (HCMV) and $\gamma$-herpesviruses (EBV) that express the GFP (green fluorescent protein) as a reporter for monitoring the courses of an in vitro infection, in order to determine the expression characteristics of core nuclear egress proteins. Infected cells were used for collecting consecutive samples at 2, 4 and 6 days post-infection (d p.i.) to analyze viral replication kinetics in a comparative manner. Stocks of VZV (cell-associated virus inoculi) and HCMV (cell-free supernatant virus inoculi) were used for fresh infection of primary human foreskin fibroblasts (HFFs) and EBV-positive producer cells (Akata-BX1 carrying EBV-GFP) were induced for the viral lytic cycle by chemical stimulation with TPA. Samples were analyzed by Western blot (Wb) staining procedures using a panel of virus-specific monoclonal antibodies, i.e. those directed to the viral core NEC proteins as well as the respective egress-regulating viral protein kinases (in addition to control proteins of infection such as the GFP reporter and HCMV-/EBV-encoded immediate early proteins IE1p72 or BZLF1, respectively). The NEC proteins and NEC-relevant kinases of all three viruses were expressed with early-late kinetics, mostly starting with detectable signals at $2 \mathrm{~d}$ p.i. in dependence on the multiplicity of infection (MOI) or the concentration of TPA induction (Fig. S1). The detected NEC proteins comprised molecular masses between 30-42 kDa (VZV, Orf24 30 kDa and Orf27 27-34 kDa; HCMV, pUL50 42 kDa and pUL53 38 kDa; EBV, BFRF1 37-38 kDa), while the protein kinases ranged to higher molecular-mass sizes between 42-100 kDa (the latter showing the bands of three isoforms of HCMV pUL97 70-100 kDa, (23)). Notably, several of these viral proteins were expressed in more than one distinct variety, thus also including 
additional bands derived from protein phosphorylation and other posttranslational modifications (Fig. S1) (13,23-28). The NEC association of regulatory viral protein kinases provides an essential effector function for all so far analyzed $\alpha$-, $\beta$ - and $\gamma$-herpesviral multicomponent NECs, as previously reported by our group and others $(13,26,29)$.

\section{The VZV Orf24-Orf27 heterodimeric complex is formed from monomeric protomers and displays $n M$ affinity}

Individually purified Orf24 and Orf27 proteins from VZV behave as monomers in solution and readily form a stable heterodimeric complex upon mixing (Fig. 1). This behavior, namely monomeric protomers yielding a heterodimeric core NEC, has already been reported for the $\alpha$ herpesvirus core NEC formed by the HSV-1 proteins pUL34 (groove protein) and pUL31 (hook protein) (30). However, in contrast to $\alpha$-herpesviral pUL31 proteins from HSV-1 and PRV, which cannot be studied in solution in absence of a solubility tag, the pUL31-homologous protein of VZV, i.e. Orf27, behaves differently $(16,20)$. Both Orf24 and Orf27 remain soluble after removal of the His- and GST-tag, respectively, and display circular dichroism spectra of well-folded proteins (data not shown).

To shed light on possible species-related features as well as subfamily-specific differences in core NEC formation, we purified the individual proteins from VZV, HCMV and EBV and investigated complex formation using identical experimental setups. Size exclusion chromatography experiments show that in addition to VZV, the EBV BFRF1-BFLF2 complex formation also originates from the interaction of monomeric proteins. In contrast, the HCMV pUL50-pUL53 heterodimeric complex is formed upon recombination of monomeric pUL50 with homodimeric pUL53 (Fig. 1, Fig. S2) (31). As previously reported for HCMV, only the groove protein pUL50 behaves as a monomer in solution, whereas the hook protein pUL53 is dimeric, at least in vitro with bacterially-produced truncated pUL53 (31). Moreover, the hook segment of pUL53 is responsible for pUL53 homodimerization (17,31). Interestingly however, homodimerization could not be observed under conditions of eukaryotic expression and the use of various interaction studies (32).

To gain insight into the thermodynamic profiles of the interactions of the three prototypical subfamily members, the affinities of the VZV, EBV and HCMV core NEC protein complexes were measured by isothermal titration calorimetry (ITC) and ELISA experiments. In both assay formats, 
affinities in the mid-nanomolar range $(10-90 \mathrm{nM})$ were determined for all three interactions, indicating similar stabilities of the complexes. (Table 1, Fig. 2, Fig. S3).

The EBV and HCMV affinities are slightly higher than those previously observed for the interaction of HCMV pUL50 and EBV BFRF1 with peptides presenting the hook segments of HCMV pUL53 and EBV BFLF2, respectively. The peptides only bound with $120 \mathrm{nM}$ (EBV) and 117 nM (HCMV) affinity (3). This can be easily explained by the additional contacts observed and anticipated in the complexes of the entire proteins, namely contacts formed in addition to the hookinto-groove interaction since the latter only accounts for about $80 \%$ of all contacts observed in the complexes (see also below) $(3,18)$. Please note that the $K_{D}$ for the binding of pUL50 to pUL53 is about 6 to 10-fold lower than reported previously by others $(31,33)$.

Although the binding affinities are comparable across subfamilies, the thermodynamic profiles differ between the three $\alpha$-, $\beta$ - and $\gamma$-herpesvirus members (Table 1). While in VZV and $\mathrm{EBV}$, the core NEC complex formation is enthalpy driven, complex formation in HCMV is favored by both the enthalpy and entropy terms. The latter might be a consequence of the fact that pUL53 forms homodimers by itself before yielding a heterodimeric pUL50-pUL53. This reduces the loss of molecular degrees of freedom in comparison to complex formation involving Orf27 and BFLF2, which are monomeric in absence of binding partners. Thus, the entropy loss during complex formation can be expected to be smaller in HCMV in comparison to EBV and VZV. The question, whether differences observed in the stoichiometry and thermodynamic parameters in the three prototypical NECs of the $\alpha$-, $\beta$ - and $\gamma$-herpesviruses investigated here extend to all members of the respective subfamilies, will require further investigations.

\section{Some degree of binding promiscuity regarding core NEC complex formation within subfamilies}

In order to address the question whether the core interaction of the VZV NEC Orf24-Orf27 is highly selective or displays some binding promiscuity with related herpesviral NEC homologs, a CoIP-based interaction analysis was performed. To this end, tagged versions of VZV and other herpesviral NEC proteins were analyzed by transient transfection of 293T cells in pairwise coexpression settings with autologous or nonautologous interaction partners (Fig. 3). This study, in part provides novel data (particularly for the interaction profiles of the VZV NEC proteins Orf24 and Orf27) and in other parts confirms our earlier investigations (regarding several comparative interaction profiles so far collected for $\alpha$-, $\beta$ - and $\gamma$-herpesviral NEC proteins, $(3,18,22))$. In the present study, three herpesviral NECs were used for comparison, i.e. $\alpha$-herpesvirus HSV-1 
(pUL34-pUL31), $\beta$-herpesvirus HCMV (pUL50-pUL53) and $\gamma$-herpesvirus EBV (BFRF1BFLF2). The CoIP analysis showed a clearly detectable interaction for the VZV-specific pair Orf24-Orf27 (Fig. 3, lanes 3 and 7) as well as the combinations between the two $\alpha$-herpesviral NEC proteins, i.e. VZV and HSV-1 (lanes 4 and 8). In contrast, the combinations between VZV and $\beta$ or $\gamma$-herpesviral NEC proteins were negative (lanes 5, 6, 9 and 10). This novel CoIP finding completes our previous investigations and indicates that the capacity of VZV NEC proteins to undergo heterodimeric interactions is restricted within proteins of the $\alpha$-herpesviral subfamily.

A second approach was used to substantiate this result on the level of individual cells by using confocal imaging of indirect NEC immunofluorescence stainings. To this end, HeLa cells were transfected with similar combinations of tagged versions of the selected $\alpha$-, $\beta$ - and $\gamma$ herpesviral NEC protein pairs (Fig. 4). As a new approach, extending beyond earlier investigations, the recruitment of the VZV hook protein Orf27 (Fig. 4A, panel 4) to the inner nuclear membraneassociated groove protein Orf24 (panel 10) was used as the basis of interaction analysis $(3,18,22)$. Notably, VZV Orf24 (as all herpesviral NEC groove proteins) is always found in a distinct rimlike nuclear envelope localization, while Orf27 (and other herpesviral hook proteins) is only seen in this location after Orf24-Orf27 interaction and rim recruitment. Here, an expected and pronounced nuclear rim colocalization was observed for VZV Orf27 together with VZV Orf24 (Fig. 4B, panels 5-8), and likewise HSV-1 pUL31 was recruited by VZV Orf24 to this rim colocalization (panels 9-12). The converse setting, using VZV Orf27 combined with HSV-1 pUL34 (panels 29-32), provided an almost identical rim staining pattern. However, all other combinations between VZV Orf24 or Orf27 with $\beta$ - or $\gamma$-herpesviral NEC protein counterparts lacked a comparable rim staining pattern. As a novel extension of our NEC studies, this finding was now also assessed by a quantitative evaluation of these microscopic samples. This quantitation further substantiated the perfect rim recruitment between the two VZV proteins and a very strong capacity of both, VZV groove protein Orf24 and hook protein Orf27, to undergo interaction with the HSV1 homologs, but an extremely low tendency of nonautologous, crossviral interactions outside the $\alpha$-herpesviral subfamily (Table S2). In addition to earlier studies, this statement is supported by an extended comparative analysis of confocal NEC rim recruitment patterns using different heterodimeric combinations with proteins from six herpesviruses, i.e. VZV, HSV-1, HCMV, MCMV, EBV and KSHV (Table S2). Also in this setting, the principal pattern was obtained, in that all autologous combinations with NEC pairs derived from one virus, showed strongly specific 
and quantitatively high levels of rim interaction patterns (Table S2, upper part, $\geq 95 \%$ of the entire number of signal-positive cells), with very low levels of diffuse localization signals $(<2.5 \%)$. Importantly, also here the potency of herpesviral NEC proteins to undergo nonautologous interactions with viral NEC counterparts within one subfamily was further substantiated (Table S2, middle part, combinations between HSV-1 and VZV; HCMV and MCMV, EBV and KSHV). These nonautologous interaction patterns ranged between $9 \pm 2.6 \%$ and $55 \pm 2.2 \%$ (perfect nuclear rim colocalization) or $<2.5 \%$ and $32 \pm 5.6 \%$ (partial colocalization), respectively. Notably, no nonautologous interaction between NEC proteins of viruses from different subfamilies was detected in any case (Table S2, lower part, < $2.5 \%$ ). Combined, these data confirm that the specificity profile of core NEC formation includes a subfamily-restricted capacity of mutual binding.

\section{Crystal structure of the VZV Orf24-Orf27 complex}

The structure of VZV Orf24 in complex with Orf27 was solved at $2.1 \AA$ resolution by crystallizing an Orf24::Orf27 fusion protein in which the C-terminus of Orf24 was fused to the N-terminus of Orf27 via a GGSGSGGS linker. This strategy has already been applied to two other NEC complexes before (18). The structure was solved via the molecular replacement technique with the HSV-1 core NEC as a search model (PDB entry 4ZXS, (16)) and refined to $R_{\text {work }}=21.5 \%$ and $R_{\text {free }}=25.5 \%$ (Table 2, Fig. 5). In the crystals, the asymmetric unit contains two Orf24-Orf27 heterodimers. All bioinformatics analyses were performed from here-on with the A-B and not the C-D heterodimer, since molecule A is considerably better defined than the equivalent molecule C as a result of additional crystal packing contacts and as highlighted by lower B-factors (Fig. S4).

The structures of Orf24 and Orf27 closely resemble those of other herpesvirus core NEC proteins present in the protein databank as shown by a DALI webserver search with the individual proteins (Table S3) $(34,35)$. Orf24 and Orf27 display the highest Z-scores as well as the lowest RMSD $_{\mathrm{C} \alpha}$ values of 1.1 to $1.2 \AA$ when compared to the homologous proteins pUL34 and pUL31 from the $\alpha$-herpesvirus members PRV and HSV-1. Sequence identities among these $\alpha$-herpesviral proteins are in excess of 50 \% (Table S3). In comparison, RMSD $\mathrm{C} \alpha_{\alpha}$ values between 1.9 and $2.8 \AA$, alongside with sequence identities lower than $21 \%$ are observed when comparing Orf24 and Orf27 to the corresponding proteins from $\beta$-herpesviruses, i.e. HCMV and MCMV, or to $\gamma$-herpesviruses, i.e. EBV. Obviously, the three $\alpha$-herpesvirus subfamily members share among themselves a higher sequence and structure similarity than to members from other subfamilies. Orf27 contains a C3H 
zinc-binding motif with a zinc ion bound to residues Cys128, Cys144, Cys147 and His251. This motif and the overall architecture of the complexes are highly conserved across all NECs (Fig. S5) (19).

\section{The Orf24-Orf27 interface}

As for other NECs, the Orf24-Orf27 interface can be subdivided into two areas, namely the area that involves the hook segment of Orf27 (residues 81 to 109) and the contacts that are formed between the remaining globular part of Orf27 (residues 110 to 333) and Orf24 (Fig. 5). The total contact area amounts to $1825 \AA^{2}$, and of these, $1400 \AA^{2}$ (77 \%) are contributed by residues from the hook segment. Similar values have been reported for other $\alpha$-herpesvirus NECs, namely from HSV-1 and PRV (16,20). These values also compare well with those observed for the $\beta$-herpesvirus HCMV pUL50 and pUL53 complex (1880 $\AA^{2}$ in total with $1510 \AA^{2}$ (80\%) contributed by the pUL53 hook segment) (19). In case of $\gamma$-herpesvirus EBV, only a structure of BFRF1 in complex with the hook segment of BFLF2 is available, and in this structure, the hook segment contributes $1590 \AA^{2}$ to complex formation (18).

The Orf24-Orf27 complex is formed by interactions involving four segments in each protein (Fig. 6 and Fig. S6). Segment one and two as well as the second half of segment four of Orf24 line the groove into which the hook segment of Orf27 binds. The third segment is formed by residues 113 to 119 of Orf24, and this segment is almost solely involved in interactions with the globular part of Orf27 and in particular with the 121 to 127 segment of Orf27 (see below) (Fig. 6). It should be noted that the fourth Orf24 segment is particularly large. It covers residues 137 to 188 and several secondary structure elements.

The largest contiguous Orf27 segment participating in the Orf24-Orf27 interface is the segment formed by residues 81 to 113 and which includes the hook segment (residues 81 to 109) (Fig. 6). Remarkably, of the 29 hook residues, all but three participate in binding as judged by the changes in solvent accessible surface areas in these residues upon complex formation. The segment also spans the beginning of $\beta$-strand $\beta 2_{\mathrm{H}}$ (110 to 113), which contributes an additional two residues to the interface (Fig. 6, Fig. S6 and Table S4). Three additional Orf27 segments also contribute to the interface. Of these, the segment formed by residues 121 to 127 and consisting of the loop $\beta 3_{\mathrm{H}^{-}}$ to- $\beta 4_{\mathrm{H}}$ as well as the beginning of strand $\beta 4_{\mathrm{H}}$ appears worth mentioning since also in this segment, all sequential residues participate in the interface. In total, this segment contributes $240 \AA^{2}(13.2 \%$ of $1825 \AA^{2}$ total contact area) to the Orf24-Orf27 interface (Fig. S6). 
A computational alanine scanning mutagenesis identifies five residues in Orf24 and seven residues in Orf27 that are predicted to contribute more than $2 \mathrm{kcal} \mathrm{mol}^{-1}$ to the interaction energy of the complex (Fig. S6). Of these 12 residues, three residues form a continuous interaction patch that is located outside of the hook-into-groove region (Fig. 7A). The participating Orf24 residues are Phe156 and Arg167, which are displayed from two different $\beta$-strand, namely from strands $\beta 9_{\mathrm{G}}$ and $\beta 10_{\mathrm{G}}$, respectively. The interacting Orf27 residue is Asp126, which is part of the Orf27 segment 121 to 127 discussed above and which forms a salt bridge with Arg167 from Orf24. Phe156 from Orf24 is located in immediate neighborhood to the salt bridge and forms additional hydrophobic interactions with Orf27 residues Val124 and Ala125. Interestingly, Orf24 residues Phe156 and Arg167 as well as Orf27 residue Asp126 are conserved among $\alpha$-herpesviruses but are not conserved at homologous positions in $\beta$ - and $\gamma$-herpesviruses (Fig. S7).

\section{The hook-into-groove interaction}

The hook-into-groove interaction represents the most striking single feature in all available core NECs $(3,13,21)$. Because of the contiguous nature of the hook segment and the concave shape of the complementary binding site in the groove protein, this region shows promise for being targetable by inhibitors. The latter could eventually yield novel antiherpesviral drugs. The side chains displayed by the groove region of Orf24 and the hook segment of Orf27 are chemically highly diverse and display mixed physico-chemical properties (Fig. S8). The Orf24 residues that contribute in excess of $75 \AA^{2}$ of their surface to the interaction area are Arg22, Leu25, Tyr68, Met169 and Tyr188. Similarly, the amino acids of the hook segment of Orf27 that contribute more than $75 \AA^{2}$ are Tyr83, His85, Phe87, Tyr89, Val101, Leu104 and Ile108. The intermolecular interactions these residues participate in span from densely packed hydrophobic interactions to extensive networks of polar interactions.

Inspection of the hook-into-groove interface reveals two distinct features, namely (i) an intricate network of polar interactions centered on Orf24 residue Tyr68 and Orf27 residue Tyr86 and (ii) the Orf27 Tyr83 clamp (Fig 7B and 7C). Computational alanine scanning mutagenesis identified three residues in Orf24 and six in Orf27 that are expected to contribute more than 2 kcal $\mathrm{mol}^{-1}$ to the hook-into-groove interaction interface (Fig. S6). Interestingly, these residues map almost exclusively to structural feature (i), namely a tyrosine-tyrosine-centered interaction network (Fig. 7B). Thus in (i), Orf24 residues Tyr68 (calculated $\left.\Delta \Delta \mathrm{G}=5.8 \mathrm{kcal} \mathrm{mol}^{-1}\right)$ and Arg22 (4.0 kcal mol $^{-1}$ ) participate in intermolecular interactions with Orf27 residues Glu97 (4.2 kcal mol ${ }^{-1}$ ) and 
Tyr86 (4.0 kcal mol-1) through the formation of both a tyrosine-tyrosine interaction and a bidental saltbridge. In addition, Orf27 residues Phe87 (3.1 kcal mol-1), Leu104 (2.7 kcal mol-1) and Val101 (2.6 kcal mol${ }^{-1}$ ) together with Orf24 residue Leu147 (2.3 $\mathrm{kcal} \mathrm{mol}^{-1}$ ) extend the interaction patch by adjacent hydrophobic interactions. The only additionally identified residue not participating in this patch is Tyr89 (2.7 kcal mol$\left.{ }^{-1}\right)$; its side chain points in the opposite direction and interacts with helix $\alpha 4_{G}$.

In feature (ii), the Tyr83 clamp, the tyrosine side chain displayed from hook helix $\alpha 1_{\mathrm{H}}$ becomes wedged between Orf24 residues Arg71, Pro146 and Leu147 (Fig. 7C). In addition, the hydroxyl group of Tyr83 is in hydrogen-bond distance to the NH-group of Leu147. Not surprisingly, Tyr83 corresponds to the hook residue that contributes most to the interface surface area (135 $\AA^{2}$ ) (Fig. S6B). However, its energy contribution to complex formation is estimated to be only $1.5 \mathrm{kcal} \mathrm{mol}^{-1}$ (Fig. S6B). Of note is that in both features (i) and (ii) many of the participating residues appear to be specifically well conserved in $\alpha$-herpesviruses and considerably less conserved in $\beta$ - and $\gamma$-herpesviruses (data not shown). Some of the above interactions have been highlighted before in other $\alpha$-herpesviral NECs $(16,20)$. However, none of these spotlighted the Tyr83 clamp as a potential determinant for subfamily specificity.

\section{Structural determinants of subfamily specificity}

Although initial analyses revealed many shared features between herpesviral core NEC structures, it has now become increasingly clear that core NEC formation displays subfamily-specific features. While no cross-reactivity has been observed so far between proteins from different subfamilies, nonautologous binding and binding promiscuity can be observed to various extents between NEC proteins from the same herpesviruses subfamilies (Table S2). Analyses of sequence homologies and structure comparisons provide clear hints for the molecular determinants of subfamilyspecificity. In an alignment of selected herpesviral NEC groove proteins, which includes all human herpesvirus proteins, three loop regions stand out (Fig. S7). These regions (i) participate in the NEC interface, (ii) differ in length and sequence between subfamilies but at the same time (iii) their composition displays subfamily-specific features.

Loop $\alpha 3_{\mathrm{G}}-$ to- $\beta 9_{\mathrm{G}}$ of the groove protein reaches into the space spanned by the two helices forming the hook segment. The loop harbors a salt bridge (between Glu67 and Lys137 in Orf24) that is strictly conserved in all herpesviruses but otherwise differs significantly in sequence and length between subfamilies (Fig. 8A). In $\alpha$-herpesviruses, the loop forms the clamp surrounding 
Orf27 residue Tyr83. The shortest and longest loops are observed in $\beta$ - and $\gamma$-herpesviral complexes, respectively (Fig. 7C, Fig, S7C). In both the HCMV and the EBV complexes, the loop sits as a lid on top of $\alpha 1_{\mathrm{H}}$ rather than embracing its residues as seen with the Tyr83 clamp in $\alpha$ herpesviruses (Fig. $7 C$, Fig, S9). In all NEC members, the loop $\alpha 3_{\mathrm{G}}$-to- $\beta 9_{\mathrm{G}}$ displays a number of highly conserved subfamily-specific residues (Fig. S7C).

Additional subfamily-specific differences can be observed in groove protein loop segments $\beta 6_{\mathrm{G}}$-to- $\beta 7_{\mathrm{G}}$ and $\beta 9_{\mathrm{G}}$-to- $\beta 10_{\mathrm{G}}$ (Fig. $8 B$, Fig. S7). The former loop is identical in length in $\beta$ - and $\gamma$ herpesviruses but about five residues longer in $\alpha$-herpesviruses. In contrast, loop $\beta 9_{\mathrm{G}}$-to- $\beta 10_{\mathrm{G}}$ is longer by one or two residues in $\beta$-herpesviruses in comparison to the other subfamilies (Fig. $8 B$, Fig. S7D). In both cases, it appears that the longer loops enable additional contacts with the hook protein that are missing in the subfamilies with the shorter loops. Most likely this will also hold true for $\gamma$-herpesviruses albeit so far only a structure of a truncated EBV complex is available.

Subfamily-specific features become also evident when focusing on the hook segments only (Fig. 9). Analysis of the inter-helix angle formed between hook helices $\alpha 1_{\mathrm{H}}$ and $\alpha 2_{\mathrm{H}}$ shows that this angle amounts to about $55^{\circ}$ and is highly conserved in the $\alpha$-herpesviral NECs (Table S1). An almost identical angle is also observed in the only available $\gamma$-herpesviral complex, namely in EBV BFRF1-BFLF2, while an angle of $45^{\circ}$ is seen in the $\beta$-herpesviral HCMV-specific NEC. Clearly, additional $\beta$ - and $\gamma$-herpesviral NEC structures are needed to corroborate possible subfamilyspecific inter-helix angle differences.

In all NECs, the hook structures appear to be stabilized by distinct features. Thus, a structural comparison reveals several instances of helix $\mathrm{N}$-capping such as the $\mathrm{N}$-capping of helix $\alpha 1_{\mathrm{H}}$ in both Orf27 (involving Ser81) and pUL53 (Thr60) (Fig. 9A and B). At the same time, His71 in pUL53 forms a C-terminal cap in hook helix $\alpha 1_{\mathrm{H}}$ in pUL53. While such helix capping residues can be expected to stabilize the conformation of the hook, it is striking that these residues are neither conserved across herpesvirus subfamilies nor within subfamilies (Fig. 9E) (36). The hook of BFLF2 from EBV displays also a salt bridge at its surface formed between Glu96 and Arg103 (Fig. 9C). However, this salt bridge is neither conserved across herpesviruses nor appears to be subfamily-specific although surface-located salt bridges have been shown to increase the structural stability of proteins $(37,38)$.

All $\alpha$ - and $\beta$-herpesviral hook proteins display a proline residue in the first helical turn of $\alpha 2_{\mathrm{H}}$ (Fig. 9, Fig. S7A). This proline residue might function as a helix breaker thereby disfavoring 
the formation of a contiguous $\alpha$-helix spanning both $\alpha 1_{\mathrm{H}}$ and $\alpha 2_{\mathrm{H}}$. This could help stabilizing the hook-like conformation of this segment in the prebinding state and hence most likely enhances the binding affinity of the hook. Interestingly, VZV Orf27 even displays two consecutive prolines in this region (Fig. 9A). At the same time however, none of the $\gamma$-herpesviral hook proteins display a proline at equivalent positions (Fig. S7), and the absence of such a proline residue does not appear to be particularly detrimental to the affinity of EBV BFRF1 to BFLF2 (Table 1).

When comparing the sequences of the hook segment of various herpesvirus hook proteins in detail, then it appears striking that no single residue is conserved across all herpesviruses (Fig 9E, Fig. S7A). However, a different picture emerges when analyzing the subfamilies individually. In each subfamily, a quite significant number of residues (30 to $40 \%$ of hook residues) can be observed that are strictly conserved within subfamilies including all human herpesviruses (Fig. 9E, Fig. S7A). When mapped onto the various hook segments, then it becomes obvious that these residues confer the hooks with subfamily-specific surface features. Hence, these features foster subfamily specificity of the hook-into-groove interaction in herpesvirus NECs (Fig. 9).

\section{DISCUSSION}

This report presents novel structural, biochemical and virological data on the core NEC complex of the human pathogenic $\alpha$-herpesvirus VZV. The main achievements of the study are: (i) a comparative analysis of NEC formation characteristics of three prototypical herpesviruses, namely one from each of the three herpesvirus subfamilies, (ii) the experimental elucidation of the 3D structure of the VZV core NEC Orf24-Orf27 complex, (iii) CoIP and confocal imaging data indicating that Orf24-Orf27 complex formation displays some promiscuity in a herpesvirus subfamily-restricted manner, (iv) computational alanine scanning and structural comparisons highlighting intermolecular interactions shared among $\alpha$-herpesviruses and (v) an overall structurefunction-based model that explains subfamily-specific and common herpesvirus NEC characteristics.

The specificity and selectivity of protein-protein interactions is ruled by protein shape complementarity and the physico-chemical properties of the interacting residues. Any of these may profoundly affect affinities even in the absence of marked changes in the other. In all NEC structures determined so far, the participating proteins display highly similar overall architectures and secondary structure compositions, and complex formation relies on highly similarly shaped binding surfaces. This is particularly well exemplified by the hook-into-groove interaction region, 
which is built from identical secondary structure elements in all NECs. Yet, the analyses reported here, highlight three loop regions that potentially fine-tune the shape complementarities in a subfamily-specific manner. Of particular interest is the loop $\alpha 3_{\mathrm{G}}$-to- $\beta 9_{\mathrm{G}}$ from the groove protein, which reaches into the interhelical space of the hook (Fig. 7 and 8). Since interaction specificity can arise from both positively and negatively discriminating determinants such as the inclusion of favorable interactions or the preclusion of interactions via the introduction of steric clashes, the differences in loop lengths and subfamily-specific sequence identities could allow this loop to function as a shape readout fine-tuning tool and thus represent an important determinant of subfamily specificity.

With the experimental elucidation of a third $\alpha$-herpesviruses NEC structure, namely that of VZV, it was now possible to analyze with amino acid detail subfamily-specific features and how these $\alpha$-herpesvirus-specific features differ in the $\beta$-herpesviral HCMV NEC complex and in the $\gamma$ herpesvirus EBV complex. This reveals a number of individual residue interactions, such as for example the tyrosine-tyrosine interaction network, the Tyr82 clamp and the salt bridge, that are highly conserved in $\alpha$-herpesviruses and substituted by different sets of subfamily-specific features in $\beta$ - and $\gamma$-herpesviruses. Computational alanine scanning mutagenesis identified twelve highly congruent residues estimated to contribute more than $2 \mathrm{kcal} \mathrm{mol}^{-1}$ to the free energy of complex formation. These residues from both the groove and hook protein are in direct contact with each other and participate in two functional hotspots, namely in the formation of the tyrosine-tyrosine interaction network and the salt bridge (Fig. 7). Interestingly, the Tyr82 clamp is not among these hot spots, although Tyr82 contributes as much as $135 \AA^{2}$ surface area to complex formation.

Subfamily-specific patterns of conserved amino acids can also be observed when exclusively focusing on the sequences of the hook segment (Fig. 9). While hook residues that directly interact with respective groove residues appear highly conserved, those residues that help to stabilize the overall conformation of the hook segments, namely helix-capping residues and surface salt bridges are only poorly conserved within and between subfamilies. A partial exception appears to be the presence of a proline at the beginning of $\alpha 2 \mathrm{H}$. Taken together, hook residues that directly participate in groove protein binding appear to be more conserved than residues that merely stabilize the hook conformation.

In light of a broader view on herpesvirus nuclear replication, the core NECs occupy an essential position within viral replication, in that they regulate at least three elaborate processes, namely the multicomponent recruitment of NEC-associated effector proteins, the reorganization of 
the nuclear lamina and membranes, and the docking of nuclear capsids to the sites of egress. As outlined above, the VZV core NEC displays numerous structural properties closely related to the previously characterized HSV-1 and PRV complexes. As far as the regulatory properties of the VZV NEC are concerned, the question of similar or even identical features in comparison to other $\alpha$-herpesviral or more distantly related $\beta$ - and $\gamma$-herpesviral complexes remained unclear so far, mostly due to the fact that reports on the VZV NEC and nuclear egress are limited in number to date. So far, little information has been available on whether the associated factors within the VZVspecific multicomponent NEC are shared with other herpesviruses. When comparing the available mass spectrometry-based interactomic data on NEC (for MCMV, see (39); for HCMV, see (40); for HSV-1, see (41)), it appears unlikely that the VZV core NEC binds to identical NEC-associated proteins that are possibly shared within the $\alpha$-herpesvirus subfamily. This assumption is based on the experimental finding of substantial differences in such binding profiles previously identified for the comparison of the two $\beta$-herpesviral representatives HCMV and MCMV. A comprehensive comparison of all so far identified or suggested NEC-associated proteins, both of viral and host cell origin, revealed at least as many matches as differences (13). Thus, it appears very probable that also the VZV-specific NEC may harbour several very distinct, unshared, possibly even strain- or cell type-specific binding partners, which may represent host-directed adaptations and do not stand in contrast to the common theme of NEC functionality found for all herpesviruses (42).

As far as the NEC-facilitated reorganization of the nuclear lamina as well as membranes is concerned, there is no indication to expect a VZV-specific difference. The microscopy-based and protein-protein interaction-based data on VZV-mediated rearrangement of the host cell nuclear envelope published so far are mostly consistent with those provided for HSV-1 $(12,15,43-45)$ or HCMV $(13,46)$. It should be mentioned, however, that the architecture of neuronal cells preferentially infected by VZV shows specific peculiarities not found by epithelial, lymphoid cells or fibroblasts frequently infected by other herpesviruses, so that also here some host-directed adaptation appears possible. A third point, mentioned with the docking of nuclear capsids to the sites of egress, is very likely to be highly conserved among herpesviruses in a way that the VZV structure described in the present study does not give rise to expected differences. Based on the conserved symmetry shared by $\alpha$-, $\beta$-and $\gamma$-herpesviral nuclear capsids, NECs appear to provide a general capsid docking platform at the inner leaflet of the nuclear membrane (13). As a recently accepted model that may hold true for herpesviruses of all three subfamilies, the hexameric 
arrangement of NEC heterodimers forms a coat-like lattice structure for the docking of nuclear capsids that are also comprising a partially hexameric surface symmetry $(13,47)$. Although hexameric coat-like NEC arrangements so far have only be detected for $\alpha$ - and $\beta$-herpesviruses, i.e. HSV-1, PRV and HCMV, the close structural NEC relatedness among $\alpha$-herpesviruses described by our present data strongly suggests an identical mode of NEC-capsid interaction also in the case of VZV.

Combined, this report highlights core NEC subfamily specific features in agreement with the observation that core NEC formation displays some promiscuity within subfamilies while no heterologous complexes are formed between subfamilies. In all cases however, complex formation is significantly less efficient in cases heterologous complexes are formed. Because of its central role in herpesviral replication, the inhibition of core NEC formation remains an interesting therapeutic target. The present study suggests that, while it might be possible to identify therapeutics that could possibly inhibit multiple viruses from identical subfamilies, the identification of compounds that are active across subfamily boundaries might be considerably more challenging. 


\section{EXPERIMENTAL PROCEDURES}

\section{Protein production and purification}

Plasmids for the expression of HCMV pUL53 residues 50-292, HCMV pUL50 1-175 and EBV BFRF1 1-192 were generated as previously published $(18,19)$. VZV Orf27 residues 77 to 333 (Uniprot entry: Q6QCM8, (48)) and EBV BFLF2 residues 78 to 318 (Uniprot entry: K9UT32) were each cloned into a pGEX-6P-1 vector (GE Healthcare). The constructs include an N-terminal GST affinity tag and a HRV 3C protease cleavage site (SDLEVLFQGPLGS). All remaining protein constructs were cloned into the pET28b vector (Merck Millipore). Unless otherwise stated, these constructs contain an N-terminal hexa-histidine tag followed by a thrombin cleavage site (MGSSHHHHHHSSGLVPRGSH). For the fusion protein VZV Orf24::Orf27, residues 16 to 189 of VZV Orf24 (Uniprot entry: Q6QCN1) were fused via a GGSGSGGS linker to residues 77 to 333 of VZV Orf27. VZV Orf24 by itself consists of residues 16 to 189 with a preceding methionine residue in place of the open reading frame of the pET28b vector. This deletes the original hexahistidine tag and thrombin cleavage site. Instead, a TEV protease cleavage site and a hexa-histidine tag (ENLYFQGHHHHHH) were fused to the C-terminus of the encoded protein.

Plasmids were transformed into chemically competent Escherichia coli BL21(DE3) cells (Novagen) and used to inoculate TB medium supplemented with $100 \mu \mathrm{g} / \mathrm{mL}$ of ampicillin or $50 \mu \mathrm{g} / \mathrm{mL}$ of kanamycin for pGEX-6P-1 or pET28b vectors, respectively. Protein production was induced with $0.25 \mathrm{mM}$ isopropyl 1-thio- $\beta$-D-galactopyranoside at $20^{\circ} \mathrm{C}$ for approx. $20 \mathrm{~h}$. Cells were harvested and mechanically lysed in appropriate buffers for the subsequent purification steps. VZV Orf24 was purified using a HisTrap (GE Healthcare) affinity chromatography step followed by cleavage with recombinant hexa-histidine tagged TEV protease and a HisTrap recapture step. All other hexa-histidine-tagged proteins were purified using a HisTrap (GE Healthcare) affinity chromatography step followed by thrombin cleavage. Surface lysine residues of VZV Orf24::Orf27 were chemically methylated before crystallization (49). GST fusion proteins were purified using Glutathione Sepharose HP (GE Healthcare) followed by cleavage with recombinant GST-HRV 3C protease and a GST recapture step. If necessary, additional anion exchange chromatography steps were performed. Finally, all protein samples were purified to homogeneity using Superdex 75 prep grade columns (GE Healthcare). 


\section{Complex formation monitored via gel filtration experiments}

The in vitro complex formation of individually purified NEC proteins was monitored using analytical gel filtration. 200 to $600 \mu \mathrm{g}$ (in 100 to $500 \mu \mathrm{L}$ ) of equimolar mixtures of the respective NEC proteins from HCMV (pUL50 1-175 and pUL53 50-292), EBV (BFRF1 1-192 and BFLF2 78-318) and VZV (Orf24 16-189 and Orf27 77-333) or 100 to $300 \mu \mathrm{g}$ samples of individual proteins were injected onto a Superdex 75 10/300 GL column (GE Healthcare) pre-equilibrated with $50 \mathrm{mM}$ TrisHCl, $150 \mathrm{mM} \mathrm{NaCl}, 1 \mathrm{mM}$ TCEP, pH 8 and eluted with 1.2 column volumes of the aforementioned buffer.

\section{Isothermal titration calorimetry}

For the Isothermal titration calorimetry (ITC) experiments, a Standard Volume Nano ITC (TA Instruments, New Castle, USA) with a $24 \mathrm{~K}$ gold cell was used. The solutions containing the hook and groove proteins of HCMV (pUL53 and pUL50) and VZV (Orf27 and Orf24) were dialyzed twice against $50 \mathrm{mM}$ HEPES $150 \mathrm{mM} \mathrm{NaCl} 2.5 \mathrm{mM}$ TCEP pH 7.4, the respective NEC proteins of EBV (BFLF2 and BFRF1) against 25 mM HEPES $150 \mathrm{mM} \mathrm{NaCl} 2.5$ mM TCEP pH 7.4. To minimize the heat generated by buffer mismatch, the hook and groove protein of each pair were dialyzed simultaneously against the same buffer. The groove protein was titrated into the hook protein solution in all experiments (100 $\mu \mathrm{M}$ pUL50 into $14 \mu \mathrm{M}$ pUL53, $50 \mu \mathrm{M}$ Orf24 into 8-9 $\mu \mathrm{M}$ Orf27 and 50-90 $\mu \mathrm{M}$ BFRF1 into 8-12 $\mu \mathrm{M}$ BFLF2). Each measurement was performed in triplicates with degassed solutions, consisting of 25 incremental titrations ( 1 x $5 \mu \mathrm{L}, 24$ x $10 \mu \mathrm{L})$ interspaced by $480 \mathrm{~s}$ time intervals at $25^{\circ} \mathrm{C}$ and $150 \mathrm{rpm}$ stirring rate. Blank titrations were performed by titrating each groove protein into buffer. The data were corrected using these and processed with the software NanoAnalyze (v3.11.0, TA Instruments).

\section{ELISA}

High binding Immulon microtiter plates were coated overnight at $4{ }^{\circ} \mathrm{C}$ with the hook proteins Orf27, BFLF2 and pUL53, respectively $[1 \mu \mathrm{g} / \mathrm{ml}$ (pUL50) and $5 \mu \mathrm{g} / \mathrm{ml}$ (BFLF2 and Orf27), respectively, in $0.1 \mathrm{M}$ sodium carbonate buffer, $\mathrm{pH}$ 9.5]. Unspecific binding was blocked with $1 \%$ BSA in 0.1 M phosphate buffer, $\mathrm{pH} 7.2$, for $3 \mathrm{~h}$. Plates were then incubated with the His-tagged groove proteins (Orf24, BFRF1 and pUL50, respectively) at two-fold serial dilutions, starting at $586 \mathrm{nM}, 531 \mathrm{nM}$, and $567 \mathrm{nM}$, respectively, for 3 h. Bound protein was detected using anti-His- 
HRP conjugate (Sigma; 1:10,000). All proteins and antibodies were in $0.1 \mathrm{M}$ phosphate buffer, pH 7.2, containing $0.1 \%$ BSA and $0.01 \%$ Tween 20 . Plates were washed four times with $0.01 \%$ Tween 20 in $0.1 \mathrm{M}$ phosphate buffer, $\mathrm{pH}$ 7.2, after each incubation step. Plates were developed with OPD ( $1 \mathrm{mg} / \mathrm{ml}$ ) in the presence of $0.03 \% \mathrm{H}_{2} \mathrm{O}_{2}$ for approximately $5 \mathrm{~min}$ in the dark. After the reaction was stopped with $2 \mathrm{M} \mathrm{H}_{2} \mathrm{SO}_{4}$, absorbance was read at $492 \mathrm{~nm}$.

\section{Cell culture, virus stocks and infection experiments}

Human embryonic kidney epithelial cells HEK 293T and cervix carcinoma epithelial cells HeLa (ATCC) were cultivated at $37^{\circ} \mathrm{C}, 5 \% \mathrm{CO}_{2}$ and $80 \%$ humidity using Dulbecco's modified Eagle medium (DMEM, 11960044, ThermoFisher Scientific). Primary human foreskin fibroblasts were cultivated in minimal essential medium (MEM), Akata-BX1 cells in RMI 1640 medium (AkataBX1 EBV-GFP, recombinant expression module selected under $350 \mu \mathrm{g} / \mathrm{ml}$ geneticin supplementation) (50,51). Cell culture medium was supplemented with $1 \mathrm{x}$ GlutaMAX ${ }^{\mathrm{TM}}$ (35050038, ThermoFisher Scientific), $10 \mu \mathrm{g} / \mathrm{ml}$ gentamicin and $10 \%$ fetal bovine serum (FBS, F7524, Sigma-Aldrich). Primary human foreskin fibroblasts (HFFs, own repository of primary cell cultures) were propagated as described previously $(25,52)$ and infectious stocks of HCMV strain AD169-GFP and VZV strain Oka-GFP were produced on HFFs and used for infection experiments according to standard procedures (53-55).

\section{Transient plasmid transfection}

Transient transfection of 293T cells was performed using polyethyleneimine-DNA complexes (Sigma-Aldrich) as described previously (56). HeLa cells were transfected by the use of Lipofectamine 2000 (Thermo Fisher Scientific) according to the manufacturer's instructions. Plasmids were used as described earlier (18,24-26,29).

\section{Antibodies}

The antibodies used for CoIP, Wb and indirect immunofluorescence (IF) analyses were as follows: mAb-BZLF1 (Santa Cruz, Sc-53904), mAb-IE1p72 (kindly provided by William Britt, University of Alabama, Birmingham, AL, USA), mAb-BFRF1 (kindly provided by Antonella Farina, University of Rome, Italy; (57)), mAb-lamin A/C (ab108595, Abcam, Cambridge, United Kingdom), mAb-HA (Clone 7, H9658, Sigma), pAb-HA (Signalway Eurogentec), mAb-HA-HRP (12013819001, Roche), mAb-Flag (F1804, Sigma), pAb-Flag (F7425, Sigma Aldrich), mAb-Flag- 
HRP (A8592, Sigma Aldrich), mAb-GFP (11814460001, Roche), mAb- $\beta$-Actin (A5441, Sigma Aldrich, St. Louis, MO, USA), anti-mouse Alexa 555 (A-21422, ThermoFisher Scientific), antirabbit Alexa 488 (A-11008, ThermoFisher Scientific). Specifically, the series of HCMV-, VZVand EBV-specific monoclonals, clones: mAb-UL50.01, mAb-UL53.01, mAb-UL97.01, mAbOrf24 VZ 24.01, mAb-Orf27 VZ 27.01, mAb-Orf47 VZ 47.01, mAb-Orf66 VZ 66.08 and mAb BGLF4.01 was produced by the Center of Proteomics (https://products.capri.com.hr) and the research laboratory of Stipan Jonjic (University of Rijeka, Rijeka, Croatia; $(28,40,58,59)$ ). For the generation of mAb-BGLF4.01, recombinant full-length BGLF4 (EBV strain B95-8) was produced and purified from a commercially available Leishmania expression system (Jena Bioscience, Germany; https://www.jenabioscience.com). BALB/c mice were injected subcutaneously with recombinantly expressed protein $(50 \mu \mathrm{g})$ in complete Freund's adjuvant. Two weeks later, mice were boosted with the same protein in incomplete Freund's adjuvant by injecting a two-thirds volume subcutaneously and a one-third volume intraperitoneally. After an additional 2-week period, the sera of immunized mice were screened for antibody titers against the immunogen by using an enzyme-linked immunosorbent assay (ELISA). The best responders were additionally boosted i.p. with the immunogen dissolved in phosphate-buffered saline (PBS). Three days later, spleen cells were collected and, after lysis of red blood cells, fused with SP2/0 myeloma cells at a ratio of 1:1. The cells were seeded onto 96-well tissue culture plates in $20 \%$ RPMI 1640 medium containing hypoxanthine, aminopterin, and thymidine for hybridoma selection. The cultures were screened for mAbs reactive against immunogens by using an ELISA. Positive mother wells were expanded and cloned.

\section{Coimmunoprecipitation analysis (CoIP)}

For CoIP analysis, 293T cells were seeded into $10 \mathrm{~cm}$ dishes with a density of 5 x 106 cells and used for transient transfection with expression plasmids. Two to three d post-transfection, CoIP was performed as described previously (26). Antibody-coupled Dynabeads (25 $\mu \mathrm{g} / \mathrm{ml}, 10002 \mathrm{D}$, ThermoFisher Scientific) were used to obtain specific immunoprecipitates and CoIP samples were further analyzed by standard SDS-PAGE and Western blot (Wb) procedures.

\section{Indirect immunofluorescence (IF) staining and confocal laser-scanning microscopy}

Transiently transfected HeLa cells were grown on coverslips, fixed at 2-3 d p.t. with $10 \%$ formalin solution (10 min, room temperature) and permeabilized by incubation with $0.2 \%$ Triton X-100 
solution (15 $\mathrm{min}, 4^{\circ} \mathrm{C}$ ). Indirect immunofluorescence staining was performed by incubation with primary antibodies as indicated for $60 \mathrm{~min}$ at $37^{\circ} \mathrm{C}$, followed by incubation with dye-conjugated secondary antibodies for $30 \mathrm{~min}$ at $37^{\circ} \mathrm{C}$. Cells were mounted with Vectashield Mounting Medium containing DAPI (H-1700, Vector Laboratories, Burlingame, CA, USA) and analyzed using a TCS SP5 confocal laser-scanning microscope (Leica Microsystems, Wetzlar, Germany). Images were processed using the LAS AF software (Leica Microsystems) and Photoshop CS5 (Adobe Inc., San José, CA, USA).

\section{Crystallization}

The fusion protein VZV Orf24::Orf27 was screened for crystallization conditions using the sitting drop technique. Methylated samples were concentrated to 10 and $15 \mathrm{mg} / \mathrm{ml}$ in a buffer consisting of $50 \mathrm{mM}$ TrisHCl, $50 \mathrm{mM} \mathrm{NaCl}, 5 \mathrm{mM}$ DTT and pH 8.0. Crystallization droplets were set up by mixing $2 \mu \mathrm{l}$ protein and $1 \mu \mathrm{l}$ reservoir solution. Diffraction quality crystals were obtained at $20{ }^{\circ} \mathrm{C}$ with a reservoir solution consisting of $0.09 \mathrm{M}$ Bis-Tris $\mathrm{pH} 5.5,0.63$ to $0.72 \mathrm{M}\left(\mathrm{NH}_{4}\right)_{2} \mathrm{SO}_{4}, 2.7 \%$ PEG 3350 and $4 \%$ formamide. Crystals grew within five to ten days to sizes of $300 \times 20 \times 10 \mu \mathrm{m}^{3}$. The crystals were flash-frozen in liquid nitrogen after addition of $20 \%$ ethylene glycol to a protein droplet.

\section{Data collection and structure refinement}

A 2.1 Å resolution diffraction data set was collected at beamline P14 at DESY synchrotron in Hamburg from crystals of VZV Orf24::Orf27. Data were processed with program XDS and datasets from two isomorphous crystals were merged using XSCALE (60). Initial phases were obtained with the molecular replacement technique with program PHENIX_PHASER using the structure of the HSV-1 nuclear egress complex as a search model (PDB entry code 4ZXS) (16,61). The structure was completed and corrected using either the PHENIX program AUTOBUILD or manually using program COOT (61,62). Crystallographic data collection and refinement statistics are summarized in Table 2. The model was refined to completion via alternating cycles of automated coordinate refinement with PHENIX and manual building with program COOT. The $\mathrm{RMSD}_{\mathrm{C} \alpha}$ values were calculated using the DALI webserver (34). All structure illustrations were drawn using Pymol (63). Changes in accessible surface areas were calculated with program AREAIMOL and interhelix angles with program HELIXANG, both from the CCP4 suite (64). 


\section{Computational analyses}

The in silico alanine scan was done using the PSSM algorithm with default settings of the program FOLD-X (version 5) (65). The multiple sequence alignment was generated with the TEXSHADE package (66). Information from structure-based pairwise alignments was used to ensure a proper alignment in regions of low sequence conservation. For the alignment, the same virus sequences were used as in the previous alignment published in Marschall et al. (3).

\section{DATA AVAILABILITY}

Accession code Protein Data Bank: The coordinates and structure factors have been deposited with the Protein Data Bank under accession code 7PAB.

\section{ACKNOWLEDGMENTS}

The synchrotron MX data were collected at beamline P14 operated by EMBL Hamburg at the PETRA III storage ring (DESY, Hamburg, Germany). We would like to thank Gleb Bourenkov for the assistance in using the beamline. M.M. greatly appreciates the excellent technical assistance by Christina Wangen (Virology, FAU). We are very grateful for our long-term cooperation partners providing very valuable materials and detection tools, i.e. Benedikt Kaufer for the supply with VZV-GFP (Virology, FU Berlin; Ref.), Rona Scott and Lindsey Hutt-Fletcher for providing AkataBX1/EBV-GFP (Dept. Microbiology and Immunology, Louisiana State Univ. LSUHSC, Shreveport, LA, USA).

\section{CONFLICT OF INTEREST}

The authors declare that they have no conflicts of interest with the contents of this article.

\section{FOOTNOTES}

This research was supported by Deutsche Forschungsgemeinschaft (MA 1289/8-1, EI 423/4-1 and MU 1477/10-1). 


\section{ADDITIONAL INFORMATION}

\section{Supplementary information}

Correspondence and requests for materials should be addressed to M.M. and Y.A.M.

\section{REFERENCES}

1. Roizman, B., and Baines, J. (1991) The diversity and unity of Herpesviridae. Comp Immunol Microbiol Infect Dis 14, 63-79

2. Bollaerts, K., Riera-Montes, M., Heininger, U., Hens, N., Souverain, A., Verstraeten, T., and Hartwig, S. (2017) A systematic review of varicella seroprevalence in European countries before universal childhood immunization: deriving incidence from seroprevalence data. Epidemiol Infect 145, 2666-2677

3. Marschall, M., Häge, S., Conrad, M., Alkhashrom, S., Kicuntod, J., Schweininger, J., Kriegel, M., Losing, J., Tillmanns, J., Neipel, F., Eichler, J., Muller, Y. A., and Sticht, H. (2020) Nuclear Egress Complexes of HCMV and Other Herpesviruses: Solving the Puzzle of Sequence Coevolution, Conserved Structures and Subfamily-Spanning Binding Properties. Viruses 12, 683

4. Tsutsui, Y. (2009) Effects of cytomegalovirus infection on embryogenesis and brain development. Congenit Anom (Kyoto) 49, 47-55

5. Rawlinson, W. D., Boppana, S. B., Fowler, K. B., Kimberlin, D. W., Lazzarotto, T., Alain, S., Daly, K., Doutre, S., Gibson, L., Giles, M. L., Greenlee, J., Hamilton, S. T., Harrison, G. J., Hui, L., Jones, C. A., Palasanthiran, P., Schleiss, M. R., Shand, A. W., and van Zuylen, W. J. (2017) Congenital cytomegalovirus infection in pregnancy and the neonate: consensus recommendations for prevention, diagnosis, and therapy. Lancet Infect Dis 17, e177-e188

6. Jha, H. C., Banerjee, S., and Robertson, E. S. (2016) The Role of Gammaherpesviruses in Cancer Pathogenesis. Pathogens 5, 18

7. Oladunni, F. S., Horohov, D. W., and Chambers, T. M. (2019) EHV-1: A Constant Threat to the Horse Industry. Front Microbiol 10, 2668

8. Raaperi, K., Orro, T., and Viltrop, A. (2014) Epidemiology and control of bovine herpesvirus 1 infection in Europe. Vet $J$ 201, 249-256

9. Pomeranz, L. E., Reynolds, A. E., and Hengartner, C. J. (2005) Molecular biology of pseudorabies virus: impact on neurovirology and veterinary medicine. Microbiol Mol Biol Rev 69, 462-500

10. Britt, W. J., and Prichard, M. N. (2018) New therapies for human cytomegalovirus infections. Antiviral Res 159, 153-174

11. Perera, M. R., Wills, M. R., and Sinclair, J. H. (2021) HCMV Antivirals and Strategies to Target the Latent Reservoir. Viruses 13, 817

12. Hellberg, T., Passvogel, L., Schulz, K. S., Klupp, B. G., and Mettenleiter, T. C. (2016) Nuclear Egress of Herpesviruses: The Prototypic Vesicular Nucleocytoplasmic Transport. Adv Virus Res 94, 81-140

13. Marschall, M., Muller, Y. A., Diewald, B., Sticht, H., and Milbradt, J. (2017) The human cytomegalovirus nuclear egress complex unites multiple functions: Recruitment of effectors, nuclear envelope rearrangement, and docking to nuclear capsids. Rev Med Virol 27 
14. Mettenleiter, T. C., Muller, F., Granzow, H., and Klupp, B. G. (2013) The way out: what we know and do not know about herpesvirus nuclear egress. Cell Microbiol 15, 170-178

15. Bigalke, J. M., and Heldwein, E. E. (2017) Have NEC Coat, Will Travel: Structural Basis of Membrane Budding During Nuclear Egress in Herpesviruses. Adv Virus Res 97, 107141

16. Bigalke, J. M., and Heldwein, E. E. (2015) Structural basis of membrane budding by the nuclear egress complex of herpesviruses. EMBO J 34, 2921-2936

17. Lye, M. F., Sharma, M., El Omari, K., Filman, D. J., Schuermann, J. P., Hogle, J. M., and Coen, D. M. (2015) Unexpected features and mechanism of heterodimer formation of a herpesvirus nuclear egress complex. EMBO J 34, 2937-2952

18. Muller, Y. A., Häge, S., Alkhashrom, S., Hollriegl, T., Weigert, S., Dolles, S., Hof, K., Walzer, S. A., Egerer-Sieber, C., Conrad, M., Holst, S., Losing, J., Sonntag, E., Sticht, H., Eichler, J., and Marschall, M. (2020) High-resolution crystal structures of two prototypical beta- and gamma-herpesviral nuclear egress complexes unravel the determinants of subfamily specificity. J Biol Chem 295, 3189-3201

19. Walzer, S. A., Egerer-Sieber, C., Sticht, H., Sevvana, M., Hohl, K., Milbradt, J., Muller, Y. A., and Marschall, M. (2015) Crystal Structure of the Human Cytomegalovirus pUL50pUL53 Core Nuclear Egress Complex Provides Insight into a Unique Assembly Scaffold for Virus-Host Protein Interactions. J Biol Chem 290, 27452-27458

20. Zeev-Ben-Mordehai, T., Weberruss, M., Lorenz, M., Cheleski, J., Hellberg, T., Whittle, C., El Omari, K., Vasishtan, D., Dent, K. C., Harlos, K., Franzke, K., Hagen, C., Klupp, B. G., Antonin, W., Mettenleiter, T. C., and Grunewald, K. (2015) Crystal Structure of the Herpesvirus Nuclear Egress Complex Provides Insights into Inner Nuclear Membrane Remodeling. Cell Rep 13, 2645-2652

21. Bigalke, J. M., and Heldwein, E. E. (2016) Nuclear Exodus: Herpesviruses Lead the Way. Annu Rev Virol 3, 387-409

22. Häge, S., Sonntag, E., Borst, E. M., Tannig, P., Seyler, L., Bauerle, T., Bailer, S. M., Lee, C. P., Muller, R., Wangen, C., Milbradt, J., and Marschall, M. (2020) Patterns of Autologous and Nonautologous Interactions Between Core Nuclear Egress Complex (NEC) Proteins of alpha-, beta- and gamma-Herpesviruses. Viruses 12

23. Webel, R., Solbak, S. M. O., Held, C., Milbradt, J., Gross, A., Eichler, J., Wittenberg, T., Jardin, C., Sticht, H., Fossen, T., and Marschall, M. (2012) Nuclear import of isoforms of the cytomegalovirus kinase pUL97 is mediated by differential activity of NLS1 and NLS2 both acting through classical importin-alpha binding. J Gen Virol 93, 1756-1768

24. Häge, S., Sonntag, E., Svrlanska, A., Borst, E. M., Stilp, A. C., Horsch, D., Muller, R., Kropff, B., Milbradt, J., Stamminger, T., Schlotzer-Schrehardt, U., and Marschall, M. (2021) Phenotypical Characterization of the Nuclear Egress of Recombinant Cytomegaloviruses Reveals Defective Replication upon ORF-UL50 Deletion but Not pUL50 Phosphosite Mutation. Viruses 13

25. Sonntag, E., Milbradt, J., Svrlanska, A., Strojan, H., Häge, S., Kraut, A., Hesse, A. M., Amin, B., Sonnewald, U., Coute, Y., and Marschall, M. (2017) Protein kinases responsible for the phosphorylation of the nuclear egress core complex of human cytomegalovirus. $J$ Gen Virol 98, 2569-2581

26. Sonntag, E., Hamilton, S. T., Bahsi, H., Wagner, S., Jonjic, S., Rawlinson, W. D., Marschall, M., and Milbradt, J. (2016) Cytomegalovirus pUL50 is the multi-interacting determinant of the core nuclear egress complex (NEC) that recruits cellular accessory NEC components. J Gen Virol 97, 1676-1685 
27. Schmeiser, C., Borst, E., Sticht, H., Marschall, M., and Milbradt, J. (2013) The cytomegalovirus egress proteins pUL50 and pUL53 are translocated to the nuclear envelope through two distinct modes of nuclear import. J Gen Virol 94, 2056-2069

28. Lenac Rovis, T., Bailer, S. M., Pothineni, V. R., Ouwendijk, W. J., Simic, H., Babic, M., Miklic, K., Malic, S., Verweij, M. C., Baiker, A., Gonzalez, O., von Brunn, A., Zimmer, R., Fruh, K., Verjans, G. M., Jonjic, S., and Haas, J. (2013) Comprehensive analysis of varicella-zoster virus proteins using a new monoclonal antibody collection. J Virol 87, 6943-6954

29. Milbradt, J., Auerochs, S., Sticht, H., and Marschall, M. (2009) Cytomegaloviral proteins that associate with the nuclear lamina: components of a postulated nuclear egress complex. J Gen Virol 90, 579-590

30. Bigalke, J. M., Heuser, T., Nicastro, D., and Heldwein, E. E. (2014) Membrane deformation and scission by the HSV-1 nuclear egress complex. Nat Commun 5, 4131

31. Sam, M. D., Evans, B. T., Coen, D. M., and Hogle, J. M. (2009) Biochemical, biophysical, and mutational analyses of subunit interactions of the human cytomegalovirus nuclear egress complex. J Virol 83, 2996-3006

32. Kicuntod, J., Alkhashrom, S., Häge, S., Diewald, B., Muller, R., Hahn, F., Lischka, P., Sticht, H., Eichler, J., and Marschall, M. (2021) Properties of Oligomeric Interaction of the Cytomegalovirus Core Nuclear Egress Complex (NEC) and Its Sensitivity to an NEC Inhibitory Small Molecule. Viruses 13

33. Leigh, K. E., Sharma, M., Mansueto, M. S., Boeszoermenyi, A., Filman, D. J., Hogle, J. M., Wagner, G., Coen, D. M., and Arthanari, H. (2015) Structure of a herpesvirus nuclear egress complex subunit reveals an interaction groove that is essential for viral replication. Proc Natl Acad Sci U S A 112, 9010-9015

34. Holm, L. (2020) DALI and the persistence of protein shape. Protein Sci 29, 128-140

35. Rose, P. W., Prlic, A., Altunkaya, A., Bi, C., Bradley, A. R., Christie, C. H., Costanzo, L. D., Duarte, J. M., Dutta, S., Feng, Z., Green, R. K., Goodsell, D. S., Hudson, B., Kalro, T., Lowe, R., Peisach, E., Randle, C., Rose, A. S., Shao, C., Tao, Y. P., Valasatava, Y., Voigt, M., Westbrook, J. D., Woo, J., Yang, H., Young, J. Y., Zardecki, C., Berman, H. M., and Burley, S. K. (2017) The RCSB protein data bank: integrative view of protein, gene and 3D structural information. Nucleic Acids Res 45, D271-D281

36. Serrano, L., and Fersht, A. R. (1989) Capping and alpha-helix stability. Nature 342, 296299

37. Perl, D., Mueller, U., Heinemann, U., and Schmid, F. X. (2000) Two exposed amino acid residues confer thermostability on a cold shock protein. Nat Struct Biol 7, 380-383

38. Kriegel, M., Wiederanders, H. J., Alkhashrom, S., Eichler, J., and Muller, Y. A. (2021) A PROSS-designed extensively mutated estrogen receptor alpha variant displays enhanced thermal stability while retaining native allosteric regulation and structure. Sci Rep 11, 10509

39. Lemnitzer, F., Raschbichler, V., Kolodziejczak, D., Israel, L., Imhof, A., Bailer, S. M., Koszinowski, U., and Ruzsics, Z. (2013) Mouse cytomegalovirus egress protein pM50 interacts with cellular endophilin-A2. Cell Microbiol 15, 335-351

40. Milbradt, J., Kraut, A., Hutterer, C., Sonntag, E., Schmeiser, C., Ferro, M., Wagner, S., Lenac, T., Claus, C., Pinkert, S., Hamilton, S. T., Rawlinson, W. D., Sticht, H., Coute, Y., and Marschall, M. (2014) Proteomic analysis of the multimeric nuclear egress complex of human cytomegalovirus. Molecular \& cellular proteomics : MCP 13, 2132-2146 
41. Liu, Z., Kato, A., Oyama, M., Kozuka-Hata, H., Arii, J., and Kawaguchi, Y. (2015) Role of Host Cell p32 in Herpes Simplex Virus 1 De-Envelopment during Viral Nuclear Egress. J Virol 89, 8982-8998

42. Ouwendijk, W. J. D., Dekker, L. J. M., van den Ham, H. J., Lenac Rovis, T., Haefner, E. S., Jonjic, S., Haas, J., Luider, T. M., and Verjans, G. (2020) Analysis of Virus and Host Proteomes During Productive HSV-1 and VZV Infection in Human Epithelial Cells. Front Microbiol 11, 1179

43. Bailer, S. M. (2017) Venture from the Interior-Herpesvirus pUL31 Escorts Capsids from Nucleoplasmic Replication Compartments to Sites of Primary Envelopment at the Inner Nuclear Membrane. Cells 6

44. Wild, P., Kaech, A., Schraner, E. M., Walser, L., and Ackermann, M. (2017) Endoplasmic reticulum-to-Golgi transitions upon herpes virus infection. F1000Res 6, 1804

45. Heldwein, E. E., and Smith, G. A. (2020) Alphaherpesviruses: Molecular Biology, Host Interactions and Control, Caister Academic Press

46. Lye, M. F., Wilkie, A. R., Filman, D. J., Hogle, J. M., and Coen, D. M. (2017) Getting to and through the inner nuclear membrane during herpesvirus nuclear egress. Curr Opin Cell Biol 46, 9-16

47. Hagen, C., Dent, K. C., Zeev-Ben-Mordehai, T., Grange, M., Bosse, J. B., Whittle, C., Klupp, B. G., Siebert, C. A., Vasishtan, D., Bauerlein, F. J., Cheleski, J., Werner, S., Guttmann, P., Rehbein, S., Henzler, K., Demmerle, J., Adler, B., Koszinowski, U., Schermelleh, L., Schneider, G., Enquist, L. W., Plitzko, J. M., Mettenleiter, T. C., and Grunewald, K. (2015) Structural Basis of Vesicle Formation at the Inner Nuclear Membrane. Cell 163, 1692-1701

48. The UniProt Consortium. (2017) UniProt: the universal protein knowledgebase. Nucleic Acids Res 45, D158-D169

49. Walter, T. S., Meier, C., Assenberg, R., Au, K. F., Ren, J., Verma, A., Nettleship, J. E., Owens, R. J., Stuart, D. I., and Grimes, J. M. (2006) Lysine methylation as a routine rescue strategy for protein crystallization. Structure 14, 1617-1622

50. Molesworth, S. J., Lake, C. M., Borza, C. M., Turk, S. M., and Hutt-Fletcher, L. M. (2000) Epstein-Barr virus $\mathrm{gH}$ is essential for penetration of $\mathrm{B}$ cells but also plays a role in attachment of virus to epithelial cells. $J$ Virol 74, 6324-6332

51. Lin, R., Heeke, D., Liu, H., Rao, E., Marshall, J. D., Chio, V., Cataniag, F., Yu, L., Zuo, F., and McCarthy, M. P. (2017) Development of a robust, higher throughput green fluorescent protein (GFP)-based Epstein-Barr Virus (EBV) micro-neutralization assay. J Virol Methods 247, $15-21$

52. Häge, S., Horsch, D., Stilp, A. C., Kicuntod, J., Muller, R., Hamilton, S. T., Egilmezer, E., Rawlinson, W. D., Stamminger, T., Sonntag, E., and Marschall, M. (2020) A quantitative nuclear egress assay to investigate the nucleocytoplasmic capsid release of human cytomegalovirus. J Virol Methods 283, 113909

53. Hutterer, C., Eickhoff, J., Milbradt, J., Korn, K., Zeittrager, I., Bahsi, H., Wagner, S., Zischinsky, G., Wolf, A., Degenhart, C., Unger, A., Baumann, M., Klebl, B., and Marschall, M. (2015) A novel CDK7 inhibitor of the Pyrazolotriazine class exerts broad-spectrum antiviral activity at nanomolar concentrations. Antimicrob Agents Chemother 59, 20622071

54. Marschall, M., Freitag, M., Weiler, S., Sorg, G., and Stamminger, T. (2000) Recombinant green fluorescent protein-expressing human cytomegalovirus as a tool for screening antiviral agents. Antimicrob Agents Chemother 44, 1588-1597 
55. Tischer, B. K., Kaufer, B. B., Sommer, M., Wussow, F., Arvin, A. M., and Osterrieder, N. (2007) A self-excisable infectious bacterial artificial chromosome clone of varicella-zoster virus allows analysis of the essential tegument protein encoded by ORF9. $J$ Virol 81, 1320013208

56. Schregel, V., Auerochs, S., Jochmann, R., Maurer, K., Stamminger, T., and Marschall, M. (2007) Mapping of a self-interaction domain of the cytomegalovirus protein kinase pUL97. J Gen Virol 88, 395-404

57. Farina, A., Santarelli, R., Gonnella, R., Bei, R., Muraro, R., Cardinali, G., Uccini, S., Ragona, G., Frati, L., Faggioni, A., and Angeloni, A. (2000) The BFRF1 gene of EpsteinBarr virus encodes a novel protein. $J$ Virol 74, 3235-3244

58. Milbradt, J., Sonntag, E., Wagner, S., Strojan, H., Wangen, C., Lenac Rovis, T., Lisnic, B., Jonjic, S., Sticht, H., Britt, W. J., Schlotzer-Schrehardt, U., and Marschall, M. (2018) Human Cytomegalovirus Nuclear Capsids Associate with the Core Nuclear Egress Complex and the Viral Protein Kinase pUL97. Viruses 10

59. Steingruber, M., Socher, E., Hutterer, C., Webel, R., Bergbrede, T., Lenac, T., Sticht, H., and Marschall, M. (2015) The Interaction between Cyclin B1 and Cytomegalovirus Protein Kinase pUL97 is Determined by an Active Kinase Domain. Viruses 7, 4582-4601

60. Kabsch, W. (2010) Xds. Acta Crystallogr D Biol Crystallogr 66, 125-132

61. Liebschner, D., Afonine, P. V., Baker, M. L., Bunkoczi, G., Chen, V. B., Croll, T. I., Hintze, B., Hung, L. W., Jain, S., McCoy, A. J., Moriarty, N. W., Oeffner, R. D., Poon, B. K., Prisant, M. G., Read, R. J., Richardson, J. S., Richardson, D. C., Sammito, M. D., Sobolev, O. V., Stockwell, D. H., Terwilliger, T. C., Urzhumtsev, A. G., Videau, L. L., Williams, C. J., and Adams, P. D. (2019) Macromolecular structure determination using X-rays, neutrons and electrons: recent developments in Phenix. Acta Crystallogr D Struct Biol 75, 861-877

62. Emsley, P., Lohkamp, B., Scott, W. G., and Cowtan, K. (2010) Features and development of Coot. Acta Crystallogr D Biol Crystallogr 66, 486-501

63. DeLano, W. (2003) The PyMOL Molecular Graphics System. DeLano Scientific LLC, San Carlos, CA

64. Winn, M. D., Ballard, C. C., Cowtan, K. D., Dodson, E. J., Emsley, P., Evans, P. R., Keegan, R. M., Krissinel, E. B., Leslie, A. G., McCoy, A., McNicholas, S. J., Murshudov, G. N., Pannu, N. S., Potterton, E. A., Powell, H. R., Read, R. J., Vagin, A., and Wilson, K. S. (2011) Overview of the CCP4 suite and current developments. Acta Crystallogr D Biol Crystallogr 67, 235-242

65. Schymkowitz, J., Borg, J., Stricher, F., Nys, R., Rousseau, F., and Serrano, L. (2005) The FoldX web server: an online force field. Nucleic Acids Res 33, W382-388

66. Beitz, E. (2000) TEXshade: shading and labeling of multiple sequence alignments using LATEX2 epsilon. Bioinformatics 16, 135-139 


\section{TABLES AND FIGURES}

\section{Table 1}

Binding parameters between hook and groove proteins in VZV, HCMV and EBV

\begin{tabular}{|l|l|l|l|l|l|l|l|}
\hline & \multicolumn{3}{|l|}{ ITC measurements } & ELISA \\
\hline & $\begin{array}{l}\text { Protein } \\
\text { titrated into } \\
\text { the cell }\end{array}$ & $\begin{array}{l}\text { Protein } \\
\text { in cell }\end{array}$ & $\mathrm{K}_{\mathrm{d}}[\mathrm{nM}]^{\mathrm{a}}$ & $\mathrm{n}$ & $\begin{array}{l}\Delta \mathrm{H} \\
{[\mathrm{kJ} / \mathrm{mol}]}\end{array}$ & $\begin{array}{l}-\mathrm{T} \Delta \mathrm{S} \\
{[\mathrm{kJ} / \mathrm{mol}]^{\mathrm{b}}}\end{array}$ & $\begin{array}{l}\mathrm{EC}_{50} \\
{[\mathrm{nM}]}\end{array}$ \\
\hline VZV & Orf24 & Orf27 & $11.5 \pm 0.2$ & 0.6 & $-91.9 \pm 1.0$ & $46.6 \pm 1.0$ & 49.2 \\
\hline HCMV & pUL50 & pUL53 & $19.8 \pm 4.6$ & 0.9 & $-27.0 \pm 0.1$ & $-17.0 \pm 0.5$ & 11.6 \\
\hline EBV & BFRF1 & BFLF2 & $85.6 \pm 40.5$ & 0.7 & $-63.3 \pm 0.5$ & $22.8 \pm 1.5$ & 34.4 \\
\hline
\end{tabular}

${ }^{a}$ Experiments were performed in triplicates.

b $\mathrm{T}=298.15 \mathrm{~K}$ 


\section{Table 2}

\section{Crystallographic data collection, phasing and refinement statistics.}

\begin{tabular}{|c|c|}
\hline PDB deposition code & $7 \mathrm{PAB}$ \\
\hline \multicolumn{2}{|l|}{ Data collection } \\
\hline Space group & $\mathrm{P} 2{ }_{1}$ \\
\hline \multicolumn{2}{|l|}{ Cell dimensions } \\
\hline$a, b, c(\AA)$ & 76.0135 .05158 .22 \\
\hline$\alpha, \beta, \gamma\left({ }^{\circ}\right)$ & 9093.6990 \\
\hline Wilson B factor $\left(\AA^{2}\right)$ & 51.07 \\
\hline Wavelength $(\AA)$ & 0.9763 \\
\hline Resolution $(\AA)$ & $19.96-2.1(2.175-2.1)^{a}$ \\
\hline$R_{\text {meas }}(\%)$ & $14.3(378)$ \\
\hline$R_{\text {pim }}(\%)$ & $4.1(105)$ \\
\hline$I / \sigma(I)$ & $10.2(0.72)$ \\
\hline$C C_{1 / 2}(\%)$ & $0.999(0.463)$ \\
\hline$C C^{*}(\%)$ & $1(0.796)$ \\
\hline Completeness (\%) & $98.97(99.53)$ \\
\hline Multiplicity & $11.9(12.9)$ \\
\hline \multicolumn{2}{|l|}{ Refinement } \\
\hline Resolution range $(\AA)$ & $19.96-2.1(2.175-2.1)$ \\
\hline No. of unique reflections & $49198(4890)$ \\
\hline Reflections used for $R_{\text {free }}$ & $3679(351)$ \\
\hline$R_{\text {work }}(\%)$ & $21.52(38.48)$ \\
\hline$R_{\text {free }}(\%)$ & $25.45(39.18)$ \\
\hline$C C_{\text {work }}(\%)$ & $0.962(0.687)$ \\
\hline$C C_{\text {free }}(\%)$ & $0.939(0.674)$ \\
\hline \multicolumn{2}{|l|}{ Ramachandran (\%) } \\
\hline favored/outlier & $97.62 / 0.0$ \\
\hline Total no. of atoms & 6675 \\
\hline Protein & 6495 \\
\hline Ligands & 12 \\
\hline Solvent & 168 \\
\hline \multicolumn{2}{|l|}{$B$-factors $\left(\AA^{2}\right)$} \\
\hline Average & 79.36 \\
\hline Protein & 79.49 \\
\hline Ligands & 111.93 \\
\hline Solvent & 72.15 \\
\hline No. of TLS groups & 21 \\
\hline \multicolumn{2}{|l|}{ R.m.s deviations } \\
\hline Bond lengths $(\AA)$ & 0.002 \\
\hline Bond angles $\left({ }^{\circ}\right)$ & 0.49 \\
\hline
\end{tabular}

${ }^{a}$ Values in parentheses refer to the highest resolution shell. 

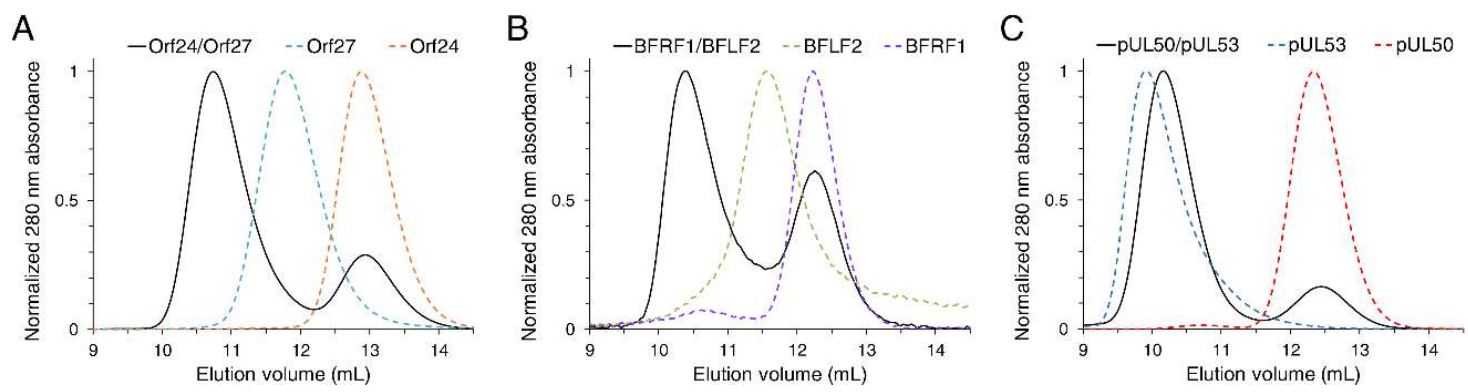

Figure 1. Stoichiometry of core NEC formation.

$A$, Core NEC formation in VZV in comparison to complex formation in $B, \mathrm{EBV}$ and $C$, HCMV as analyzed using a gel filtration experiment. A, VZV Orf24 (residues 16-189, orange, dashed line), Orf27 (77-333, cyan, dashed line) or both (black, solid line). B, EBV BFRF1 (1-192, purple, dashed line), BFRF2 (78-318, green, dashed line) or both (black, solid line). C, HCMV pUL50 (1-175, red, dashed line), pUL53 (50-292, blue, dashed line) or both (black, solid line). 

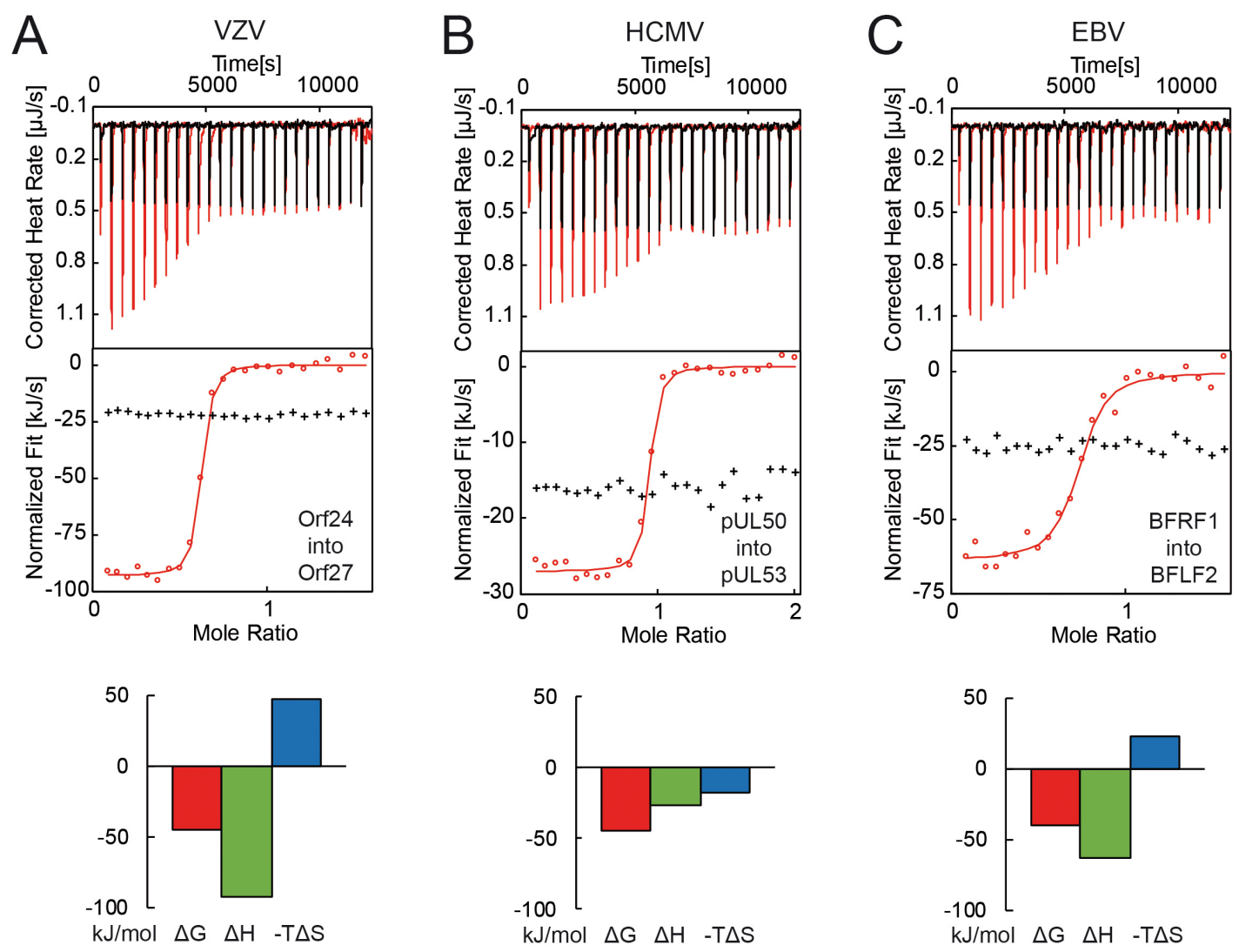

Figure 2. Determination of the thermodynamic parameters of VZV ORF24-ORF27 complex formation in comparison to HCMV and EBV via ITC.

$A$, VZV Orf24-Orf27, $B$, HCMV pUL50-pUL53 and $C$, EBV BFRF1-BFLF2 complex formation. ITC traces, the integrated heats (circles) and the fitted binding models (lines) of the NEC formations are shown in red, the corresponding blank titrations in black (crosses). 


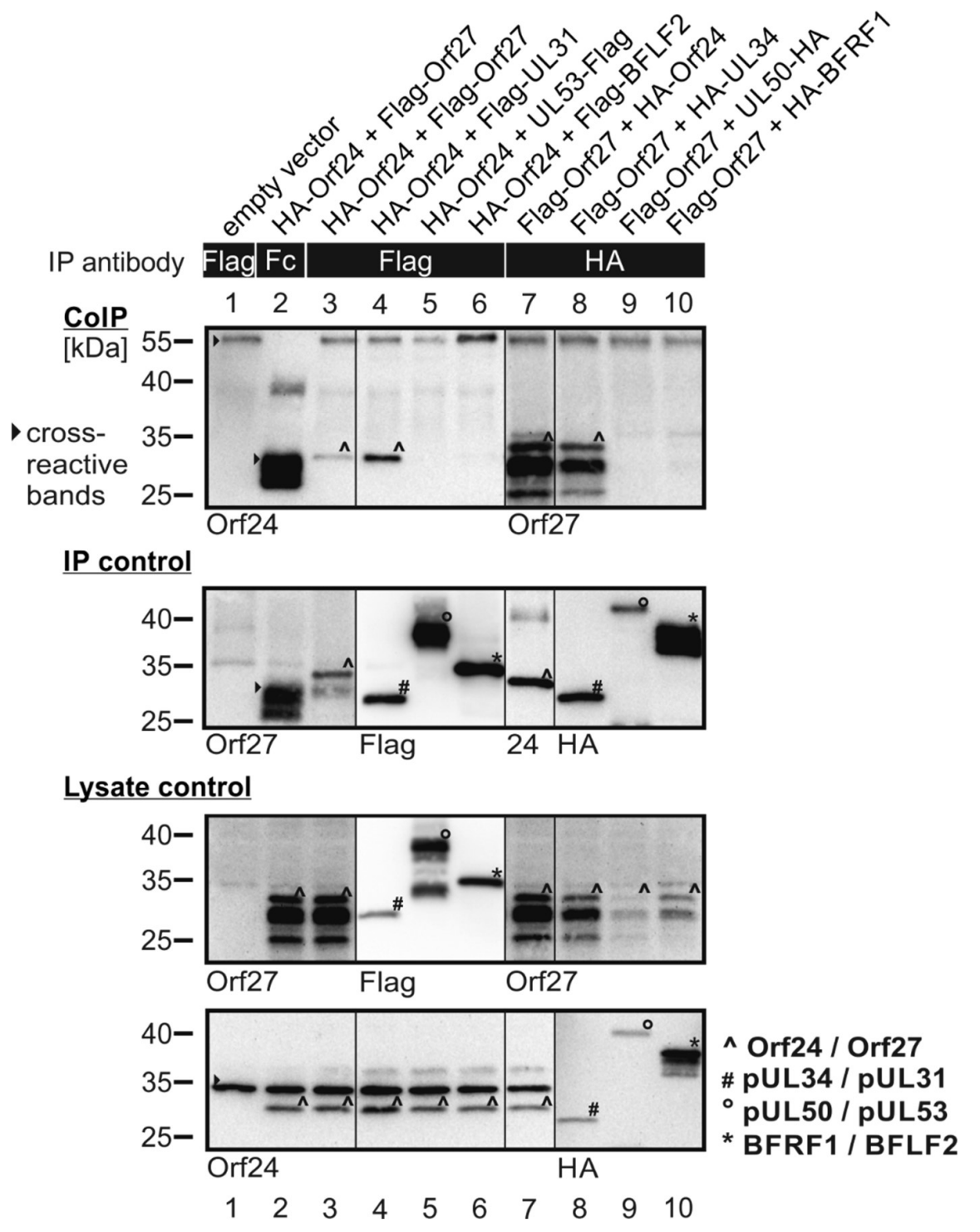

Figure 3. CoIP-based interaction analysis of VZV NEC proteins in pairwise coexpression with autologous or nonautologous herpesviral NEC protein homologs (the latter derived from HSV-1, HCMV and EBV).

293 T cells were transiently transfected with expression plasmids coding for HA-tagged and Flag-tagged versions of NEC proteins as indicated. At three d post-transfection (d p.t.), cells were lysed and HA- or Flag-tagged proteins were immunoprecipitated using mAbFlag, mAb-HA, or a nonreactive antibody Fc fragment as a specificity control. Total lysate controls taken prior to the IP and CoIP samples were subjected to standard $\mathrm{Wb}$ analysis 
using tag-specific antibodies as indicated (lysate control). Successful immunoprecipitation was monitored by $\mathrm{Wb}$ staining with the respective tag- or protein-specific antibodies (IP control). Positive CoIP reactions were marked by symbols $(\wedge, \#, o, *$; see explanation at the lower right) as referring to the identical symbols on the control panels (filled triangle, cross-reactive, non-specific bands, additionally serving as a loading marker). Note the positive signals obtained for CoIP reactions with autologous or nonautologous NEC pairs derived from the same viral subfamily, but negative results obtained for combinations between different subfamilies. 
A
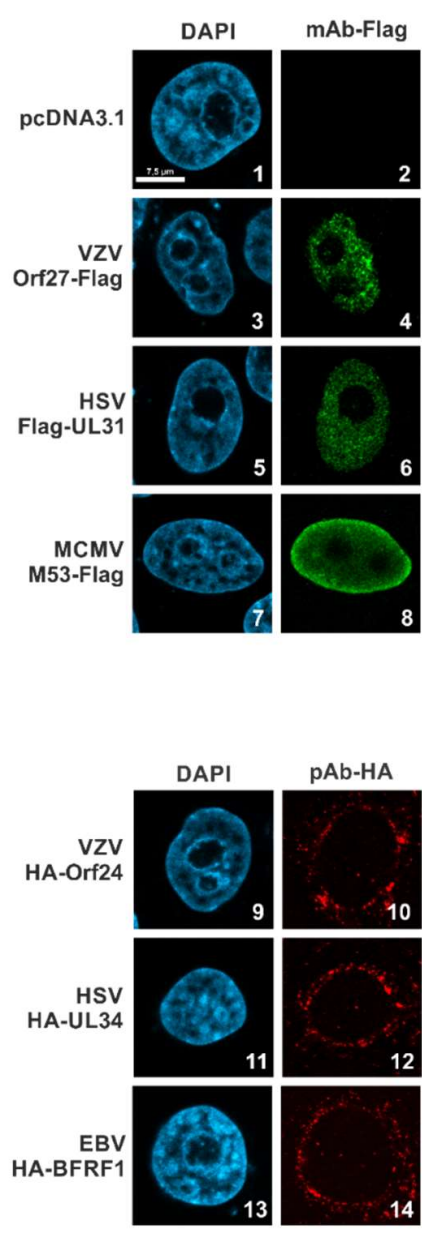

B

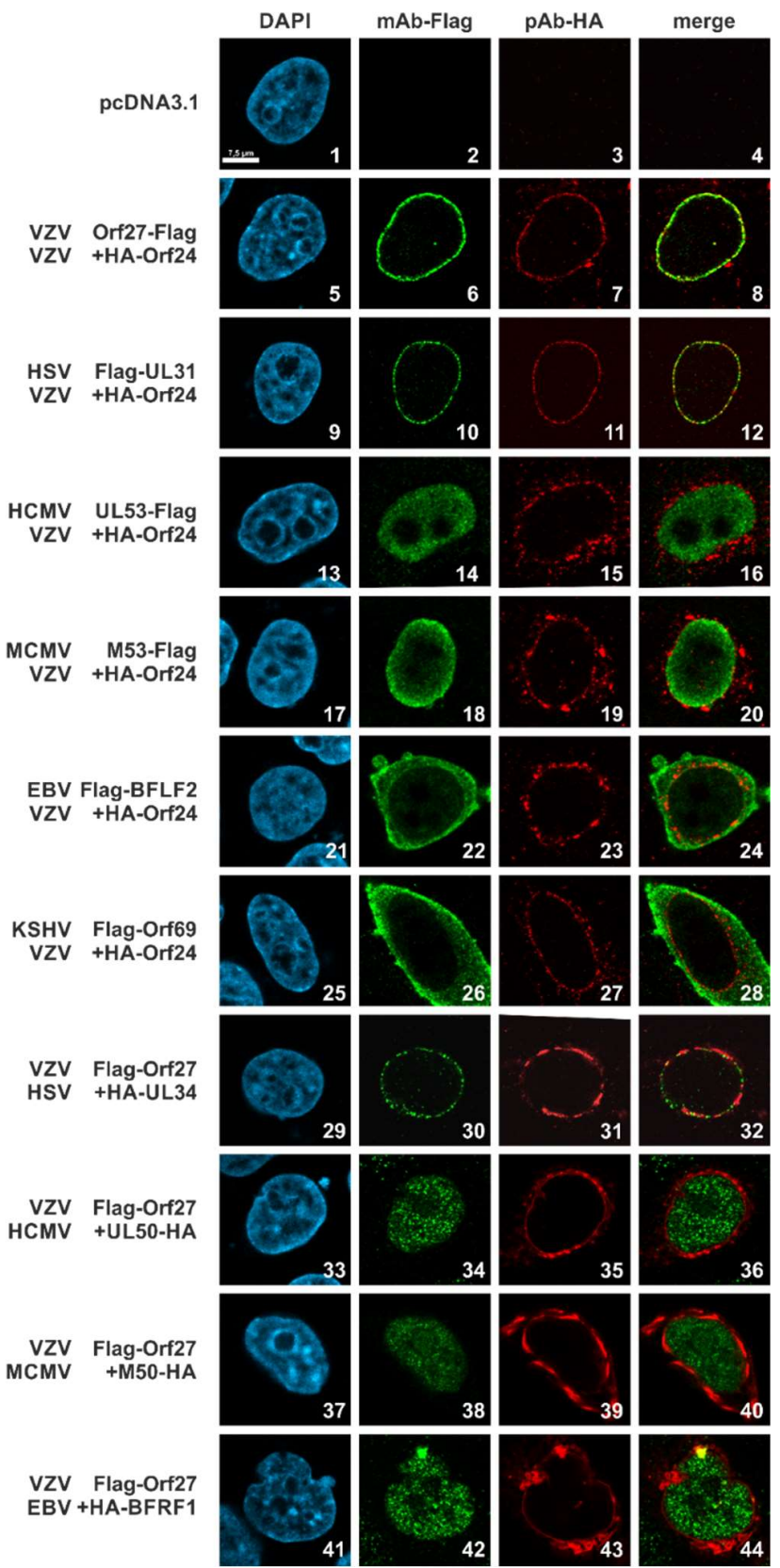

Figure 4. Pairwise transient coexpression of VZV and other herpesviral core NEC proteins.

HeLa cells were transiently cotransfected with constructs coding for the tagged versions of NEC proteins. At two d p.t., cells were fixed, used for an immunostaining with tag-specific antibodies and analyzed by confocal imaging. DAPI counterstaining indicated the morphology of nuclei of the respective cells. $A$, controls of single expression of the VZV 
NEC hook protein and homologs (panels 1-8) or the VZV NEC groove protein and homologs (panels 9-14). B, pairwise coexpression of the VZV groove (panels 5-28) or hook (panels 29-44) NEC proteins combined with their homologous herpesviral counterparts. Note the perfect nuclear rim colocalization between the VZV NEC proteins alone (Panels 5-8) or NEC counterparts within the same viral subfamily (HSV-1, panels 9-12 and 29-32), which is missing in the combinations with NEC proteins from other subfamilies (HCMV, MCMV, EBV or KSHV) 

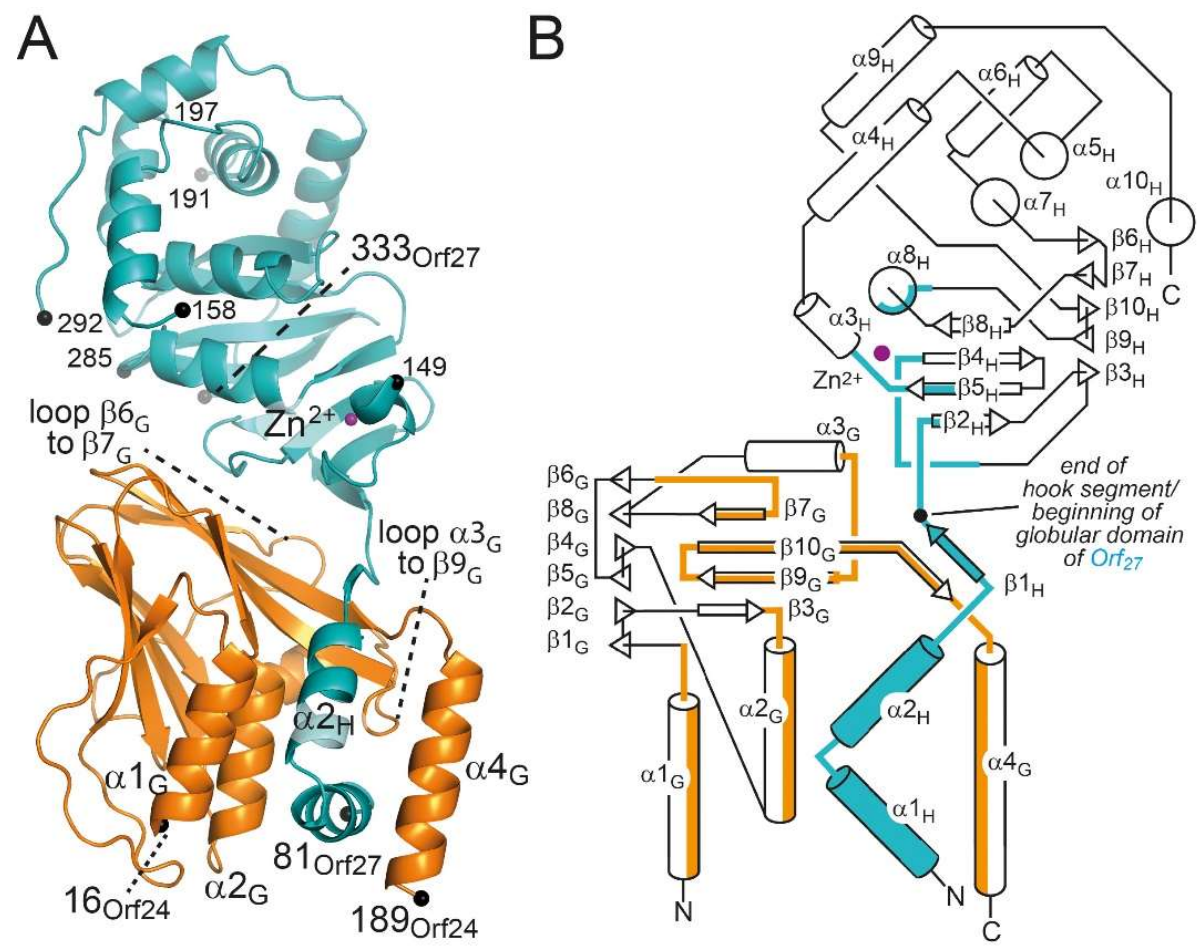

Figure 5. Structure of the VZV Orf24-Orf27 complex.

$A$, ribbon representation of the Orf24-Orf27 complex with Orf24, the groove protein, colored in orange and Orf 27 , the hook protein, colored in cyan. $B$, topology diagram of the complex. In $B$, protein segments involved in Orf24-Orf27 intermolecular contacts are colored. See Table S4 for secondary structure assignments. 


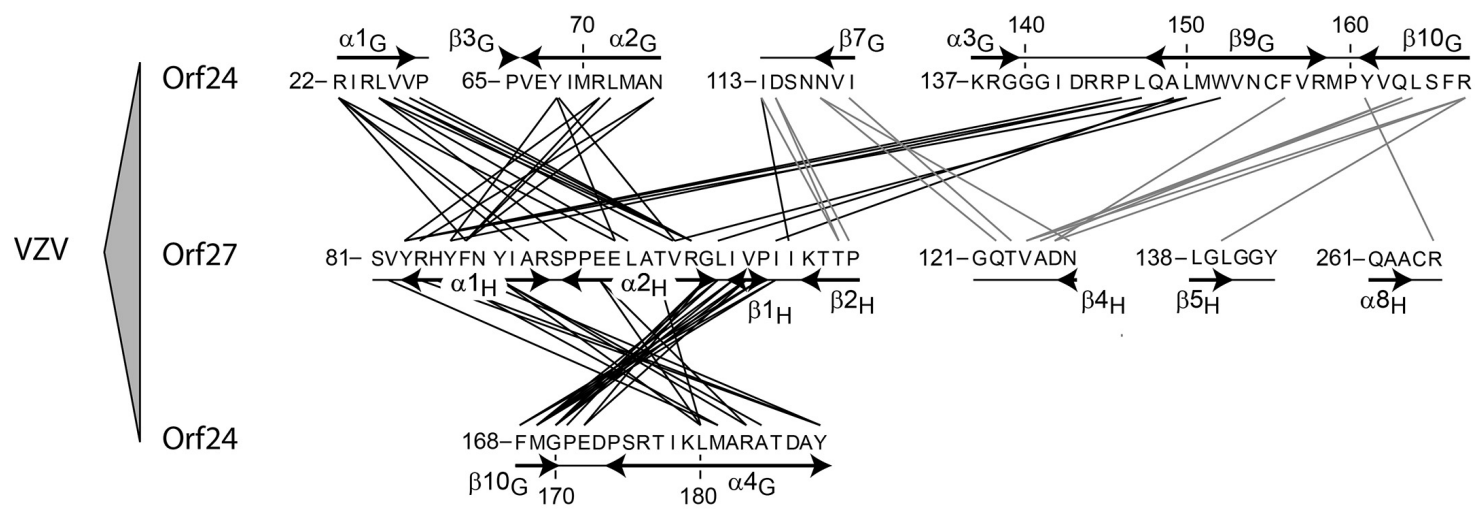

Figure 6. Intermolecular contacts in the VZV Orf24-Orf27 complex.

Interacting residues are connected and highlighted by lines based on a $3.8 \AA$ distance cutoff criterion. Interactions involving the hook segment of Orf27 (residues 81-109 containing $\alpha 1_{\mathrm{H}}, \alpha 2_{\mathrm{H}}$ and $\left.\beta 1_{\mathrm{H}}\right)$ are marked by black lines and those involving the remaining globular domain of Orf27 by grey lines. 

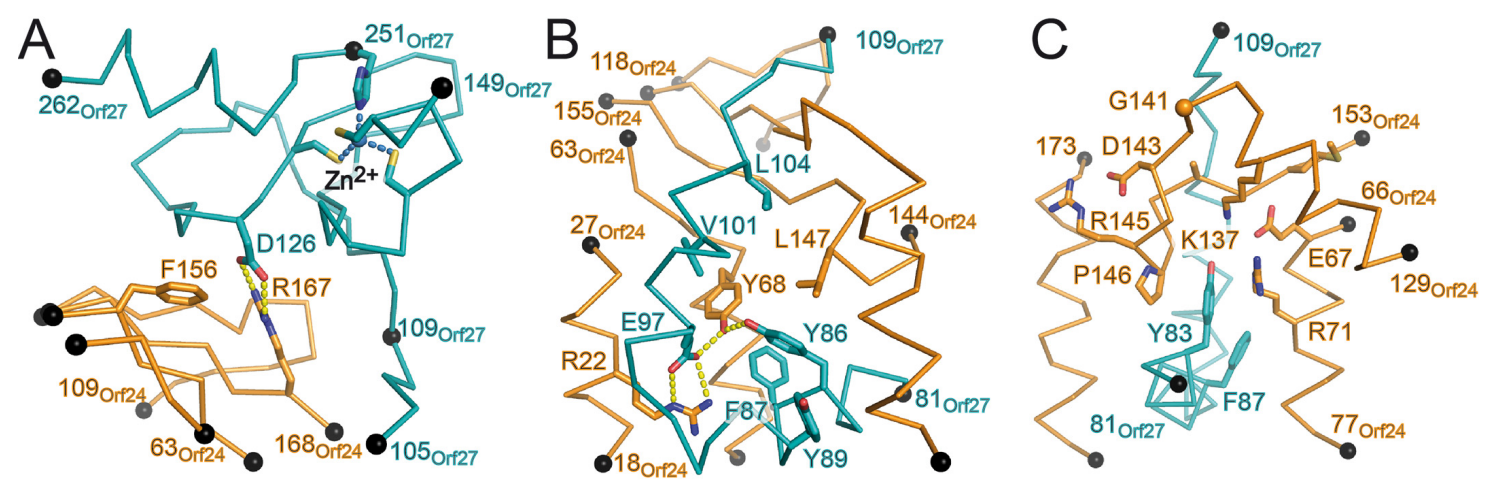

Figure 7. Atomic details of the VZV Orf24-Orf27 interactions.

$A$, interaction patch formed between Orf24 and the globular part of Orf27 as identified by computational Ala-scanning. $B$, interaction patch formed between Orf24 and the hook segment of Orf27 as identified by computational Ala-scanning. In $A$ and $B$, interface residues that contribute in excess of $2 \mathrm{kcal} \mathrm{mol}^{-1}$ to the interaction are explicitly shown. $C$, structure of the Tyr83 clamp involving the $\alpha 3_{\mathrm{G}}$-to- $\beta 9_{\mathrm{G}}$ loop (residues 129 to 153 ). Residues from this loop that are strictly conserved in a selection of Orf24-homologous proteins are displayed (see also Fig. S7). A selection of additionally conserved residues displayed from other segments of Orf24 are also shown as well as selected Orf27 residues (in cyan). The structural details in $A$ and $B$ are depicted in an orientation that is identical to that of Fig. 5. The orientation in panel $C$ corresponds to that of panel $B$ after a $90^{\circ}$ rotation around a vertical axis. 

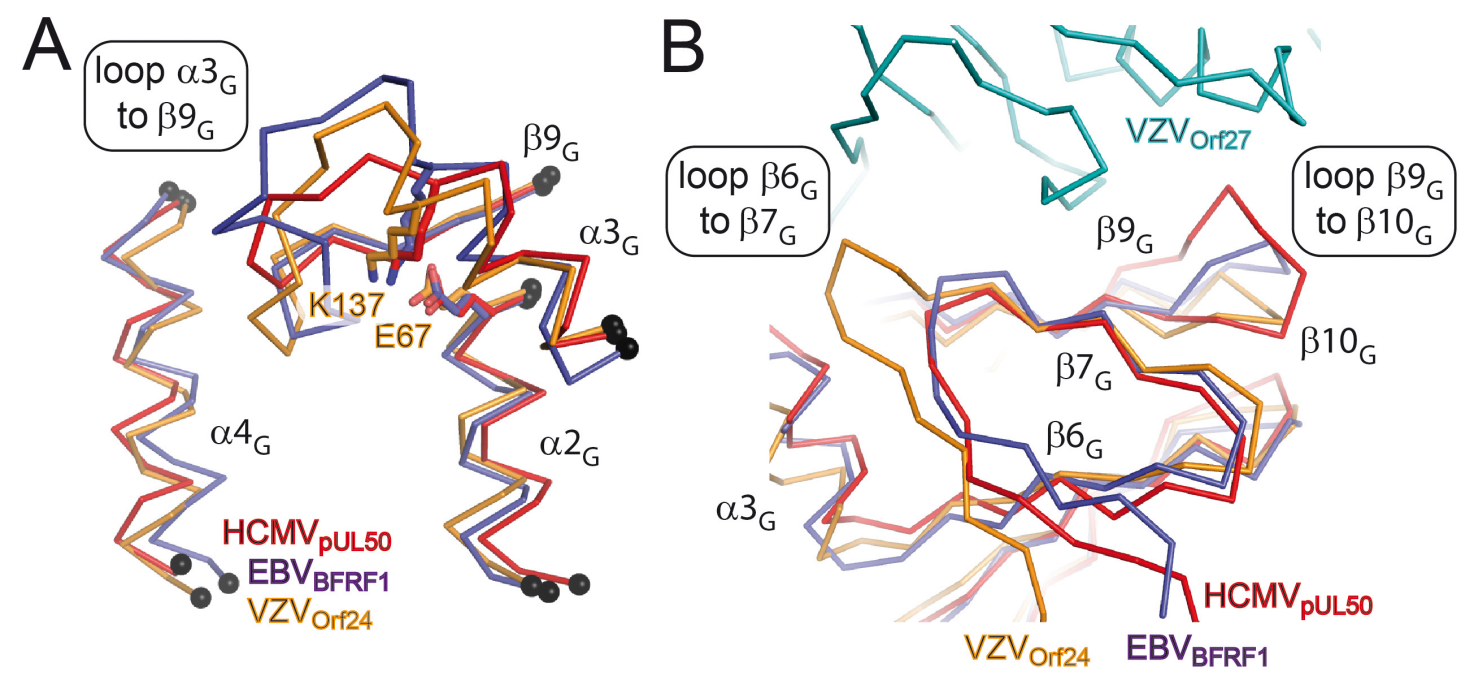

Figure 8. $\alpha$-, $\beta$ - and $\gamma$-herpesvirus subfamily differences mapped onto three different loop regions.

$A$, differences in the length of the loop $\alpha 3_{\mathrm{G}}$-to- $\beta 9_{\mathrm{G}}$ appear to be herpesvirus subfamilyspecific and give raise to different loop conformations and hook interaction patterns in VZV Orf24 (in orange), HCMV pUL50 (red) and EBV BFRF1 (mauve). The hook segments of the corresponding hook proteins have been omitted for clarity. $B$, location of two additional loop segments displaying subfamily-specific differences and involved in interactions with the globular domain of the corresponding hook proteins. The orientations of the molecules in all panels correspond to that of Fig. 5 but viewed from the backside. 


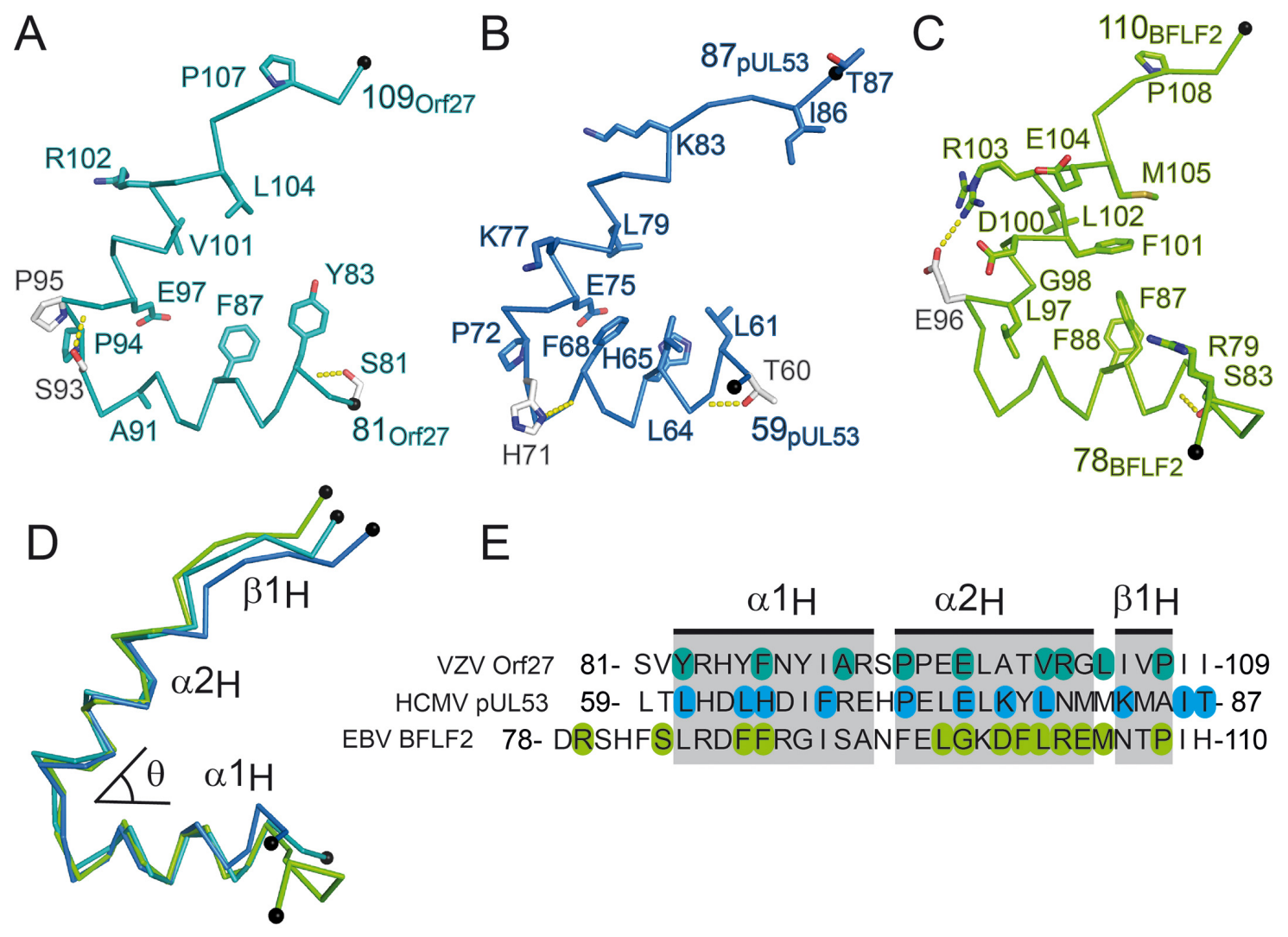

Figure 9. Subfamily-specific differences in the hook segments of VZV, HCMV and EBV.

$A$, hook segment of VZV Orf27 with residues strictly conserved in a selection of $\alpha$ herpesviral hook proteins displayed in cyan (see also Fig. S7A). $B$, hook segment of HCMV pUL53 with residues strictly conserved in a selection of $\beta$-herpesviral hook proteins displayed in blue. $C$, hook segment of EBV BFLF2 with residues strictly conserved in a selection of $\gamma$-herpesviral hook proteins displayed in green. In $A$ to $C$, residues displayed in white appear not to be subfamily-specific but contribute interesting features, such as Nor C-terminal helix capping or a surface-exposed salt bridge, to the corresponding hook segment. $D$, superposition of the hook segments of VZV, HCMV and EBV and definition of the interhelix angle $\theta$. $E$, sequence alignment of the hook segments. In panel $E$, the residues explicitly displayed in panels $A$ to $C$ are color-marked. The secondary structure elements are indicated. 